\title{
The Representation of Third Person and Its Consequences for Person-Case Effects
}

\section{Citation}

Nevins, Andrew. The representation of third person and its consequences for person-case effects. Natural Language and Linguistic Theory 25 (2007): 273-313.

\section{Published Version}

http://dx.doi.org/10.1007/s11049-006-9017-2

\section{Permanent link}

http://nrs.harvard.edu/urn-3:HUL.InstRepos:2223518

\section{Terms of Use}

This article was downloaded from Harvard University's DASH repository, and is made available under the terms and conditions applicable to Open Access Policy Articles, as set forth at http:// nrs.harvard.edu/urn-3:HUL.InstRepos:dash.current.terms-of-use\#OAP

\section{Share Your Story}

The Harvard community has made this article openly available.

Please share how this access benefits you. Submit a story.

Accessibility 


\title{
The representation of third person and its consequences for person-case effects
}

\author{
Andrew Nevins
}

Received: 13 June 2005 / Accepted: 3 July 2006 / Published online: 28 April 2007

(C) Springer Science+Business Media B.V. 2007

\begin{abstract}
In modeling the effects of the Person-Case Constraint (PCC), a common claim is that 3rd person "is not a person". However, while this claim does work in the syntax, it creates problems in the morphology. For example, characterizing the well-known "spurious se effect" in Spanish simply cannot be done without reference to 3rd person. Inspired by alternatives to underspecification that have emerged in phonology (e.g., Calabrese, 1995), a revised featural system is proposed, whereby syntactic agreement may be relativized to certain values of a feature, in particular, the contrastive and marked values. The range of variation in PCC effects is shown to emerge as a consequence of the parametric options allowed on a Probing head, whereas the representation of person remains constant across modules of the grammar and across languages.
\end{abstract}

Keywords Third person - Spurious se - Person case constraint - Me lui . Clitic clusters $\cdot$ Multiple agree $\cdot$ Person features $\cdot$ Contrastive specification

\section{Introduction: third person is a person, too!}

This study is an attempt to provide featural commensurability between syntactic researchers working on Person-Case effects (Bonet, 1991) and morphological

Conversations with and suggestions by Elena Anagnostopoulou, Karlos Arregi, Jonathan Bobaljik, Eulàlia Bonet, Seth Cable, Oana Ciucivara, Carmen Dobrovie-Sorin, Daniel Harbour, Heidi Harley, Jim Harris, Susana Huidobro, Conor Quinn, Norvin Richards, and Jochen Trommer have greatly assisted the shape and scope of this paper. Many thanks are also due to Marcel den Dikken, two anonymous $N L L T$ reviewers, and Welton Blount for their careful reading, many remarks leading to improvements in clarity and solidity of argumentation, and editorial keenness. An early version of this paper appeared in Harvard Working Papers in Linguistics Volume 11.

\footnotetext{
A. Nevins $(\varangle)$

Department of Linguistics, Harvard University,

317 Boylston Hall, Cambridge, MA 02139, UK

e-mail: nevins@fas.harvard.edu
} 
researchers working on syncretisms and paradigm structure. A simple example introduces the problem: Modern Greek and Catalan do not tolerate two 1st/2nd person (henceforth 1/2) arguments of a ditransitive verb (the strong PCC), and Spanish does not tolerate a 3 rd person dative along with a $1 / 2$ accusative within ditransitives. Taking Anagnostopoulou's (2005) account (to which this paper owes great intellectual debts) as an exemplar, we can model the PCC effects as the result of a difference in the featural representation between $1 / 2$ and 3rd person arguments. A common claim is that 3rd person "is not a person" (Kayne, 2000). However, while this claim does work in the syntax, it creates problems in the morphology. For example, characterizing the well-known "spurious se effect" in Spanish (Bonet, 1995; Perlmutter, 1971) simply cannot be done without reference to 3rd person. We must therefore seek a featural characterization of $3 \mathrm{rd}$ person that does not rob it of its ability to condition *le lo effects.

I will henceforth call proponents/analyses based on the " $3 \mathrm{rd}$ person has no person feature" view the 3noP view (e.g., among others, Anagnostopoulou (2005), Adger and Harbour (2006), Bejar and Rezac (2003), Harley and Ritter (2002)). ${ }^{1}$ In Sect. 2, I will provide a demonstration, based on evidence from Spanish clitic interactions, that 3 noP cannot be upheld. In Sect. 3, I include two additional arguments culled from the literature that support the conclusion that 3rd person must be specified for person features, in particular, [-Participant, - Author]. Section 4 contains a discussion of a formal parallel to this situation: underspecification in phonology, and Calabrese's (1995) alternative, involving relativization of processes to certain values of features.

By way of revisiting the phenomena that the 3 noP claim was originally intended for, Sect. 5 and 6 demonstrate the positive consequences of adopting the representation of third person as [-Participant, - Author] for an analysis of variation in the typology of Person-Case effects. Sections 7 and 8 explore further issues in the representation of person features as they relate to the typology of Person-Case effects. Section 9 concludes the article.

\section{Spurious se in Spanish: *me lui meets *le lo}

In this section, I demonstrate that the ban on *le lo in Spanish clitic sequences is a dissimilation rule that requires reference to a set of features exclusively borne by third person.

\subsection{Overview}

Spanish has a system of pronominal clitics that may be marked for case, person, number, and gender. These clitics occur in a cluster that is usually immediately preverbal, except in imperatives and non-finite forms, in which case it is immediately postverbal. A partial inventory is given below:

1 Proponents of the 3noP view are often rather keen on attributing it to Emile Benveniste, e.g.."The ordinary definition of the personal pronouns as containing the three terms I,you and he simply destroys the notion of 'person'" (Benveniste, 1971, p. 219); however, as far as I know, Benveniste was not concerned with the representation of third person as it pertained to concrete syntactic phenomena. My focus in this article is not on "notions of person" but on the formal representations of and operations on person features.

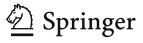


(1) Partial Clitic inventory:

me: 1 st person dat/acc

te: 2 nd person dat/acc

lo: $3 \mathrm{rd}$ acc masc

la: $3 \mathrm{rd}$ acc fem

le: 3rd dat masc/fem

$-s$ : plural on any 3 rd person, e.g., los, las, les

Clitic doubling of left-dislocated arguments may occur for both accusative (2) and dative (3) arguments:

(2) El premio, lo dieron a Pedro ayer the prize, 3rd-acc gave-pl to Pedro yesterday

The prize, they gave to Pedro yesterday.

(3) A Pedro, le dieron el premio ayer

to Pedro, 3rd-dat gave-pl the prize yesterday

To Pedro, they gave the prize yesterday.

However, there is an important constraint: 3rd dat and 3rd acc cannot occur together as clitics, (4). When a dative and an accusative argument require clitic doubling, the first clitic (the dative) undergoes morphological change, resulting in an opaque form se (an existing clitic used for reflexive, reciprocal, impersonal, and a variety of other constructions). Hence, instead of the expected sequence le lo (4), what results instead is the sequence se lo (5). This effect has been called "the spurious se" by Perlmutter (1971), since the repair to the disallowed 3rd-3rd sequence is substitution of a clitic which otherwise shouldn't surface, since there is no syntactic context in these ditransitives that otherwise requires it. ${ }^{2}$

(4) *A Pedro, el premio, le lo dieron ayer to Pedro, the prize, 3rd-dat 3rd-acc gave-pl yesterday.

(5) A Pedro, el premio, se lo dieron ayer to Pedro, the prize, se 3rd-acc gave-pl yesterday.

Though there are a variety of proposals for modeling the structural change of this rule (e.g., insertion of the "least marked" clitic, feature deletion, etc.), our focus here is on the structural description of the rule: the triggering environment. We can view this essentially as a dissimilation rule:

(6) Delete/alter the features corresponding to 3rd person on a dative when it precedes another 3rd person.

I will defer a full discussion of the features on 3rd person until Sect. 5: they are [-Participant, -Author]. We may briefly note and dismiss here the possibility of alternative formulations that do not refer to third person.

(7) "Always delete/alter dative realization in a clitic cluster, except when there is a participant feature somewhere in the clitic cluster" (alternative proposal to (6)).

2 There are a variety of proposals for why the clitic se is chosen, e.g., because it bears some phonological similarity to $l e$, and preserves the clitic status of the original position while only minimally altering the morphosyntactic contribution. See Bonet (1991) for extensive discussion. I will delay my own proposal for why se is inserted until Sect. 8, in which the representation of impersonals is discussed. 
This will not work, because a lone 3rd person dative is fine (see. (3)).

(8) "Always delete/alter dative realization when there is more than one clitic in a sequence, except when there is a participant feature elsewhere in the clitic cluster" (alternative proposal to (6)).

This will not work, because when the dative 3rd clitic is second in a cluster (e.g., following an impersonal se), nothing happens, as can be verified by (9):

(9) Se les da los honores a los generales Imp-cl 3rdpl.dat give the honors to the generals (Somebody) gives honors to the generals.

(Perlmutter, 1971:33).

We may consider next, then, a slight revision of (8):

(10) "Always delete/alter dative realization when there is more than one clitic in a sequence and it is the first clitic in the sequence, except when there is a participant feature elsewhere in the clitic cluster" (alternative proposal to (6)).

This works. However, due to the fact that 3 rd person clitics always follow 1 st person, 2nd person, and impersonal/reflexive se clitics, the only time that a 3rd person clitic will be first in a sequence of two or more clitics will be when it precedes an accusative 3rd person clitic, which is precisely the environment for the rule in (6). In other words, the quantifier "always" in the statement in (10) is deceptive, as it makes it look like this is a general deletion rule of Spanish, subject to the exceptions stated. However, given all of the exceptions that are needed to make it accurate, (10) becomes nothing more than a cumbersome restatement of a deletion rule that applies only in the exact same environment as (6). (10) is thus rephrased as (11):

(11) Delete/alter the features corresponding to 3 rd person on a dative when it precedes another clitic, and there is no participant feature in the clitic it precedes, i.e. $\neg \exists$ [Participant] in the second clitic (alternative proposal to (6)).

Incidentally, one cannot rephrase (11) as "le only occurs when immediately preverbal, otherwise it is spelled out as $s e$ ", because clitic ordering remains the same even in imperatives and in infinitives, when all clitics are postverbal. Thus, it is not true that le is immediately adjacent to the verb, either, as (12) and (13) are grammatical.

¡Escapa te le!

Escape.imper 2.refl 3.dat

Escape from him!

¡Entrega te le!

Turn-in.imper 2.refl 3.dat

Give yourself up to him!

Thus, the negative existential quantification in (11) becomes almost equivalent to saying "Delete when there is a [-Participant] feature in the neighboring clitic". However, it is couched as a sort of "licensing statement", which is somewhat bizarre: why should a "regular" deletion of 3rd person be "saved" by the presence of [+Participant] later in the cluster? On the other hand, the dissimilation rule in (6) is straightforward: the presence of two identical adjacent person feature specifications is illicit. The dissimilation rule falls into line with a number of formally identical rules 
in natural language, such as those identified by the Obligatory Contour Principle (Leben, 1973), the Double-ing filter (Ross, 1972), and, most importantly, the set of clitic constraints given by Perlmutter (1971:44) for Spanish that generally ban adjacent person specifications in a clitic cluster (recall that dative and accusative are syncretic for 1 st \& 2nd person in Spanish, and note that nos is the 1st plural clitic):

$$
\text { *te te, *me me, *nos nos, *me nos, *nos me }
$$

Returning to our focus here, the *le lo constraint, we repeat its structural description below: ${ }^{3}$

(15) Delete/alter the features corresponding to 3rd person on a dative when it precedes another 3rd person.

Perlmutter (1971:22) formulates a general set of co-occurrence filters based on the prohibition of adjacent $3 \mathrm{rd}$ person clitics: ${ }^{4}$

$$
\text { *le lo, *les lo, *le los, *le la, *le las, *les lo, *les los, *les la,*les las }
$$

A reviewer suggests that the dissimilation driving the *le lo constraint is not due to a ban on adjacent [-Participant, -Author] features, but rather due to a phonological ban on adjacent stems within a given domain. The idea is that the *le lo constraint and all of (16) is to be assimilated with *me me and *te te. I find this suggestion untenable for three reasons. First, other Romance languages allow adjacent 3rd person clitics (e.g., French le lui), while retaining the ban on *me me, *te te; moreover, Spanish disallows *nos me, which do not share phonological stems. Thus, there is little to be gained by assimilating the *le lo constraint into a general constraint on identical phonological stems.

Second, we may consider (and reject) a very specific version of this analysis, namely a ban on adjacent stems that consist only of the segment "l". To investigate this hypothesis, I created the nonce verb lar, meaning 'to kick' (as many dialects of Spanish notably lack this verb, and moreover, it is semantically similar to the double-object verb 'to give'; see Ramscar (2002), who shows that semantic similarity biases nonce irregular verb inflection). I inflected lar entirely parallel to dar 'to give', and I trained native speaker volunteers on sentences such as (17) and (18)
(17) Juan me lio la pelota
Juan 1sg.dat LAR.3sg the ball
Juan larred ( = kicked ) me the ball.
(18) Nunca te loy la pelota
Never 2sg.dat LAR.1sg the ball
Never do I lar ( = kick ) you the ball.

As dar 'to give' is analyzable as $d+a r$, the invented verb lar is analyzable as $l+a r$, and, as per the reviewer's suggestion, le is analyzable as $l+e$, the prediction of the

\footnotetext{
3 Manzini (1998) offers the suggestion that the spurious se is triggered by "competition" of two 3rd person arguments, capturing the same intuition that it is identity of person features that yields the repair by $s e$.

4 See also Grimshaw (1997), who captures the intuition that this is a language-particular dissimilation rule driven by the constraint "*XX". While this constraint is rather coarse-grained in its predictive scope, if it were to be formulated over abstract morphosyntactic person features, it would go a long way in explaining clitic cluster restrictions, as we will see in the comparison with Basque below.
} 
"No Adjacent L-stem" account is clear here. When I asked subjects how to say "We kicked him the ball", they responded as Le lamos la pelota, and not as Se lamos, thoroughly disproving the role of phonological identity in incurring dissimilation of the clitic. In short, identity at the level of morphological features, and in particular, person features, is what is needed to state the *le lo constraint of Spanish.

Finally, I will draw on suggestive comparative evidence from the Arce dialect of Italian, discussed by Pescarini (2005). Arce shows a phenomenon much like the *le lo constraint, where the first element in 3dat-3acc combination glie glie is replaced by the elsewhere locative clitic, yielding ce glie. Importantly, this "spurious ce" occurs in the 3rd.dative-3rd.partitive combination as well, where the expected glie ne also undergoes replacement of the dative by the elsewhere locative, yielding $c e n e .{ }^{5}$ The ban on adjacent 3rd.dative-3rd.partitive clitics cannot be explained by a phonological output filter; it clearly requires identity at an abstract level of morphosyntactic features.

At the same time, I would not like to wholly discount the role of phonological similarity in providing a diachronic nudge for the morphologization of (15), and for phonological factors quite generally to provide a force in the grammaticalization of a formal morphological constraint such as (15). For example, consider the fact that amn't is an impossible form in many dialects of British and North American English (Francis, 1985; Bresnan, 2001). This is arguably due to a synchronic filter banning the feature combination [+copula, +Pres, +neg, +Auth, +PSE, - singular] on a single syntactic node, which is resolved in various ways: in the dialect identified as "Nb 5 " in Francis (1985) as isn't (i.e., via deletion of [+Auth,+PSE]), while in North American English as aren't (i.e. via deletion of [-singular]). On the other hand, the fact that amn't is tolerated in the dialect identified as "Nb 1" in Francis (1985), and is even attested in children's speech (as revealed by a search conducted on CHILDES ${ }^{6}$ ) suggests that there is no active phonological constraint against this form in English; if there were, it should be rescuable in the phonology, e.g., by epenthesis of a vowel, or by deletion of one of the two coda nasals (cf. autumn autumnal). Rather, certain dialects have arguably morphologized a ban on the feature combination [+copula, +Pres, +neg, + Auth, +PSE, -singular] and respond to this morphosyntactic filter through various morphological repairs (e.g., feature deletion). While phonological pressures may play a role in shaping the diachronic development of purely morphological filters, the claim is that the synchronic representation of the ban on *amn't and the *le lo constraint is morphological in nature: a ban on morphological feature co-occurence.

\footnotetext{
5 Note that as many Romance languages allow clitic sequences such as nos lo, there is little support for a phonological ban on adjacent homorganic sonorants in a clitic cluster. Moreover, as Italian distinguishes coronal nasals and laterals from palatal nasals and laterals (with glie as palatal but ne as coronal), these two clitics cannot even be convincingly argued to share a place of articulation, casting further doubt on a phonological explanation for the Arce pattern.

6 The following three examples were culled from a search of every child in the database. Notably, none of their parents uttered amn't in the database.
}

a. Mummy I'm doing all it by myself amn't I? [ belfast/john07.cha:1435; age 4;4.1]

b. I'm doing this puzzle well amn't I? [macwhin/BOYS/boys67.cha:1464; age 3;11.18]

c. Amn't I clever? [macwhin/BOYS/boys67.cha:2292; age 3;11.18] 
In conclusion, the importance of the *le lo constraint for the present discussion is that it clearly requires reference to $3 \mathrm{rd}$ person, and cannot be formulated if $3 \mathrm{rd}$ person has no representation in the grammar.

\subsection{Support for person-feature dissimilation: the Basque $g$-/z-constraint}

In this subsection, I would like to briefly provide support for the dissimilation analysis that I have provided, in which the spurious se arises as the result of a constraint against adjacent person feature specifications. The evidence comes from work by Arregi and Nevins (2006), who investigate a pattern of unexpected agreement morphology in dialects of Bizkaian Basque, which they call the $g-/ z$ - constraint. These dialects ban agreement morphology that realizes a 1st-plural argument when a 2 nd person argument is present, and repair the configuration by deleting person features on either the $1 \mathrm{pl}$ or the 2 nd person argument. Thus, in contrast to the spurious se constraint, which bans adjacent identical values of [-Participant], the Basque $g$-/z-constraint bans adjacent identical values of [+Participant]. The data to be discussed here come from de Yrizar (1992).

In the first set of phenomena, whenever a 1st person plural dative agreement morpheme co-occurs with a 2 nd person ergative morpheme, the 1st person plural morpheme is completely deleted. This is shown in (19) for the dialect of Bermeo Occidental, where the lefthand side of the arrow shows the expected auxiliary form, while the form on the right of the arrow shows the actual auxiliary that surfaces:
(Hik guri emon) d- o-
sku- na $\rightarrow$ d-
o-
na
(You us gave) 3sg.abs- aux.trans- 1pl.dat- 2sgf.erg $\rightarrow$ 3sg.abs- aux.trans- 2sg.erg You (f.sg) [gave] it to us.
(Bermeo Occidental, Yrizar, 1992, vol.1: 486)

The deletion of $1 \mathrm{pl}$ in (20) only occurs in the environment of 2 nd person ergative. What is of interest here is that, given the same structural description (e.g., [1pl] and [2] in the same auxiliary), the dialect of Plencia Nororiental enacts a different repair: deleting the 2 nd ergative instead.

(20) (Suek gu ikusi) g- aittu- $\quad$ su $\rightarrow$ ga- ittu

(You us saw) 1pl.abs- aux.trans- 2sg.erg $\rightarrow$ 1pl.abs- aux.trans

You (pl.) [saw] us.

(Plencia Nororiental, de Yrizar, 1992, vol.1: 656)

The deletion of 2 nd ergative in (10) only occurs in the environment of $1 \mathrm{pl}$. Importantly, the placement of clitics within the Basque auxiliary is such that the absolutive clitic appears before the auxiliary root and the ergative appears after the auxiliary root. Arregi and Nevins (2006), following a tradition in the Basque literature, view this as a matter of linearization that does not reflect hierarchical structure. Therefore, both the repairs in (19) and (20) are ones which affect a clitic with [+Participant] in the same cluster as another clitic with a [+Participant] specification. We can thus understand both effects as due to the same structural description:

(21) Banned Configuration: $[+$ Participant, + Author $+\mathrm{Pl}]$ in the same clitic cluster as [+Participant].

The difference between the two dialects is that Bermeo Occidental deletes one of the offending agreement morphemes $([+$ Participant, + Author, $+\mathrm{Pl}])$ while Plencia Nororiental deletes the other ([+Participant]). If we factor out the repairs to (21), 
we can see that it is also a dissimilation rule, this time based on adjacent identical values of [+Participant]. The reader is directed to Arregi and Nevins (2006), where the repair strategies for the $g-/ z$ - constraint are presented for five dialects of Bizkaian Basque in a variety of argument-structural configurations.

To recap, the Basque $g-/ z$ - constraint is a morphological ban on adjacent identical values of the person feature [+Participant], demonstrating that dissimilation for identical person features is a formal configuration that may vary crosslinguistically in the feature that is targeted. Thus, the analysis of the spurious se constraint as the result of a dissimilation rule for adjacent values of [-Participant] receives support from the fact that dissimilation rules for adjacent identical values of person features are attested elsewhere in natural language.

\subsection{Leísmo dialects support the 3rd-person dissimilation analysis}

In this subsection, I will address one other alternative analysis for the spurious se condition, which I will show to be untenable. An inspection of (1) reveals that only 3rd person clitics are contrastive for Case; both 1st and 2nd person clitics have syncretic forms for Dative and Accusative. Thus, an interesting possible alternative dissimilation rule to (6) would be the following:

(22) Delete/alter the Case (and possibly other) features on a clitic with contrastive Case-marking when it precedes another clitic with contrastive Case-marking.

The formulation in (22) does not refer to 3rd person at all; it only makes reference to the facts of Case contrastiveness (see Laenzlinger, 1998:151-156 for an idea along the lines of (22)). ${ }^{7}$ However, the problem is that we can find dialects of Spanish in which Case is not contrastive among 3rd person clitics for animate arguments: namely, the leísmo dialects of Northern Spain. For leístas, sentences such as (23), in which the clitic $l e$ is used to double an accusative argument, are perfectly grammatical. ${ }^{8}$

Le/*lo mataron a Pedro

Le/*lo killed-3pl a Pedro

They killed Pedro.

(Leísta Spanish)

\section{Le/*lo vi a-1 professor ayer}

Le/*lo saw A-the professor yesterday

They saw the professor yesterday.

(Leísta Spanish)

Thus, in the words of Franco and Huidobro (2004, p. 219), "Mainstream leísta dialects involve a neutralization of the Accusative-Dative clitic Case distinction when the referent is animate". In addition, these speakers obey the standard specificity restriction on clitic doubling of an accusative argument that holds for direct objects in Spanish (Bleam, 1999). Thus, le cannot double a negatively quantified direct object, nor can it double a bare plural.

\footnotetext{
7 I thank Jim Harris for suggesting exploration of this alternative, and Susana Huidobro for extensive discussion of the leismo phenomena that I employ in ultimately refuting this possibility. Ivan Ortega-Santos confirmed the leísta judgements as well.

8 In the glosses below, $a$, a particle which can be used as either a preposition or a differential object marker for specific accusatives, is glossed simply as A.
} 
(25) Juan no (*le) conoció a nadie

Juan neg (*3rd) met-past.3rd A nobody

Juan didn't meet anyone.

(Bleam, 1999: 49)

(26) Juan (*les) ha conocido a lingüistas

Juan (*3rd) has met A linguists

Juan has met linguists.

(Bleam, 1999: 49)

However, for these same speakers, when le is doubling an indirect object, the specificity restriction does not hold.
Marta no le envió
su tesis a nadie
Marta neg 3rd send-past.3rd her thesis A nobody
Marta didn't send her thesis to anybody.

(Bleam, 1999: 49)

Thus, it seems that the correct conclusion is that leismo Spanish is identical to Standard Spanish with respect to the syntax of direct-object clitic doubling. When a direct object is doubled, it must be specific, whereas indirect object clitics do not require specificity of their doubled argument. Thus, the syntax of clitic doubling in leísmo Spanish is identical to Standard Spanish; the only difference lies in the morphological features specified in the clitics. In (28), I provide a partial list of the Vocabulary Items of leísmo Spanish:

\section{Leísmo Partial Clitic inventory:}

$m e: 1$ st person dat/acc

te: 2 nd person dat/acc

le: 3 rd person dat/acc

lo: 3 rd acc [-animate] masc

la: 3rd acc [-animate] fem

$-s$ : plural on any 3rd person, e.g., los, las, les

A brief note is required on the above table. I have suggested that $l o$ is specified for [-animate] arguments, while le is underspecified for animacy. This is because even in leísmo dialects, le can double an inanimate argument when it is the indirect object: ${ }^{9}$

\footnotetext{
9 A reviewer suggests an alternative, in which leísmo 3rd person clitics do not bear person features. The only way to implement this suggestion is to assume that $l o$ is specified as $[-$ animate, + acc] and that $l e$ is underspecified. Under this possibility, the spurious se rule would be framed as something like "Replace $l e$ with $s e$ when it precedes a [-animate] clitic". The reviewer suggests creating contexts with an inanimate, clitic-doubled goal, and an animate theme to arbitrate between possibilities. Under this analysis, there should be no spurious $s e$ with a [-animate] goal and a [+animate] theme; if anything, this context should yield le le or le los. On the other hand, under my analysis of 3rd-person dissimilation, there should still be a spurious se effect. My leísta informants judge (i), in which spurious $s e$ has occurred, as exceedingly preferable to (iia) or (iib):
}

(i) ? El niño, se lo dieron a-1 mundo

the-masc. child-masc., SE 3rd-sg gave-past.3pl A-the world

They gave the child to the world.

(ii) a. *El niño, le les dieron a-l mundo

b. *El niño, le los dieron a-l mundo

The noun phrase el mundo 'the world' is syntactically animate. As the contrast in (i) and (ii) for leista speakers reveals, clitic-left dislocation of el mundo must be accompanied by the [-animate] clitic. 
(29)
Le pusé azucar a-l pastel
3rd put-past.1sg sugar A-the cake
'I put sugar on the cake.'

Thus, it is arguably only $l o$ and $l a$, which are specified as being both [-animate] and accusative, that make gender distinctions in leísmo Spanish. Having established the clitic inventory of leísmo Spanish and demonstrated that dative and accusative are syncretic for 3rd person [+animate] arguments, it remains to be demonstrated that leísmo Spanish still shows the spurious se effect. And indeed, it does:
A Pedro, el premio, le
lo
dieron ayer
to Pedro, the prize, 3rd-dat 3rd-acc gave-pl yesterday
To Pedro, the prize, they gave yesterday.

(Leísmo Spanish; judgements due to S. Huidobro, I. OrtegaSantos)

(31) A Pedro, el premio, se lo dieron ayer to Pedro, the prize, se 3rd-acc gave-pl yesterday

To Pedro, the prize, they gave yesterday.

(Leísmo Spanish; judgements due to S. Huidobro, I. OrtegaSantos)

Thus, the Case-contrastiveness hypothesis (repeated below) cannot be maintained, as speakers for whom le is not contrastively specified for Case still show the spurious se effect. ${ }^{10}$

(32) Delete/alter the Case (and possibly other) features on a clitic with contrastive Case-marking when it precedes another clitic with contrastive Case-marking.

Instead, the rule for leísmo Spanish seems to be the same as that for Standard Spanish, repeated below.

Footnote 9 continued

(iii) El mundo, lo /*le ví
The world, 3rdinanim / *3rd-anim saw-1sg
I saw the world

The results in (108)-(109) confirm the fact that it is reference to 3rd person features, and not animacy (or lack thereof), that is a conditioning environment for the spurious se effect.

10 There is a very interesting side issue to pursue: when both goal and theme are animate in leísmo Spanish, the theme is realized as $l o$, yielding a spurious se output of se lo even where se le would be expected (Landa, 1995: 49). There seems to be an additional dissimilation rule on animacy that affects the second clitic in such sequences. Independent support for such a rule comes from Ormazabal and Romero 2006, who note the following contrast for leísmo Spanish:

(i)
$\mathrm{Te}$ lo
di
Cl-2p Cl-3.inanim gave-1st.

I gave it to you. or 'I gave him to you.'

$$
\begin{aligned}
& * \mathrm{Te} \text { le di } \\
& \text { Cl-2p Cl-3-anim gave-1st. } \\
& \text { I gave him to you. }
\end{aligned}
$$

I suggest a context-sensitive feature-deletion rule here: the [+animate] feature on a clitic is deleted when it follows a [+animate] indirect object clitic. Following Harbour (2003b), the default unmarked [-animate] feature is re-inserted on the syntactic terminal prior to vocabulary insertion. Thus, even though in leísmo Spanish, le is the less-specified vocabulary item, [-animate] still remains the less marked feature value. 
(33) Delete/alter the features corresponding to 3rd person on a dative when it precedes another 3rd person.

As the Person Case effects are often called *me lui effects, and seem to require that 3 rd person lacks representation of person, while the spurious se effects are, in effect, a ban on *le lo that requires reference to $3 \mathrm{rd}$ person, I call this the "*me lui meets *le lo" problem. (Note that both effects can be found in the same language, as Spanish has PCC effects). The general question that all proponents of the 3 noP view must face, then, is the following: if the feature defining "3rd person" is literally absent from the representation, how can one state a morphological rule that crucially depends on its presence?

Here, it may be useful to draw on a quotation by Will Rogers: "Nothing you can't spell will ever work." The conclusion that the spurious se facts inevitably yield is that 3rd person must have a featural representation of Person beyond "nothing".

\section{Further cases requiring reference to 3rd person features}

In this section, I will discuss two other phenomena that refer to person features borne exclusively by third person, and conclude that third person cannot be underspecified for person.

\subsection{English verbal $-s$}

Consider the distribution of English present tense verbal agreement endings, as schematized in the table below: ${ }^{11}$

\begin{tabular}{lll}
\multicolumn{1}{r}{ sg } & pl \\
1st & I play $\varnothing$ & we play $\varnothing$ \\
2nd & you play $\varnothing$ & you/y'all play $\varnothing$ \\
3rd & he/she plays & they play $\varnothing$
\end{tabular}

There is massive syncretism in this paradigm: the same form is used for every person/number combination except for 3rd person singular. The intuition here is that the form /-s/ is listed for use in the 3rd person singular, while the form $/-\varnothing /$ is the default present tense agreement ending. An implementation of this intuition in terms of the mechanisms of Vocabulary Insertion (Halle and Marantz, 1993, Noyer, 1992) and the Subset Principle (Halle, 1997) would be as follows:

(35) In the environment of $T_{\text {pres }}$ :

$/$-s/ $\leftrightarrow$ [-Participant, +Singular $]$

$|-\emptyset| \leftrightarrow$ elsewhere

Clearly, the most concise and natural representation of the syncretism in (35) is captured by an intrinsic ordering of the two items in (35), based on specification of the features that each affix realizes. However, without a featural representation for 3rd person (i.e., if 3rd person is just "the lack of features"), we cannot naturally capture the fact that when there is a 3rd person singular subject, /-s/ wins over the elsewhere item because it realizes more features.

\footnotetext{
11 I am assuming a zero morpheme, as opposed to no ending, for two reasons: one, on the assumption that the terminal node for agreement always exists in the syntax regardless of whether it is expressed by overt phonological material or not, and two, because $d o$-support, understood as driven by the need to support a tense affix, still occurs even when the affix has null content, as in Do $+\varnothing$ they play? (Halle, 1997).
} 


\subsection{Menominee suffix distribution}

There is one other recent demonstration of the fact that 3rd person must be referred to by the morphology, due to Trommer (2006). Trommer presents an analysis of agreement morphology in Menominee. Briefly, there is a set of morphemes in the independent order (the main paradigm) that are crucially sensitive to whether there is a 3rd person argument or not. If there is no third person argument, then the morpheme $-m$ is inserted (36):

(36) a. ke-pose-m, 'you embark'

b. ne-pose-m, 'I embark'.

On the other hand, if there is at least one third person argument, then the morpheme $-w$ is inserted:
a. pose-w,
'he embarks'
b. ne-nan-ek-w, 'he fetches me'
c. ne-nan-a-w, 'I fetch him'.

We can summarizing the pattern as follows:

(38) Menominee Independent Order suffix (descriptive generalization):

All arguments [+Participant]: $-m$

One argument [+Participant], one argument [-Participant]: $-w$

Both arguments [-Participant]: $-w$

As $-w$ occurs in the mixed case of a [+Part] and [-Part] argument, there is no way to make it the "elsewhere" suffix and avoid specification for it. Rather, it looks like $-w$ is specified as the suffix if there is a [-Participant] argument, and $-m$ is the elsewhere suffix (I am operating within standard assumptions here in holding that morphological realization has the ability to match features by existential quantification, but does not have access to predicates like "exactly one" instance of a feature).

$$
\begin{aligned}
& \text { Menominee Independent Order suffix: } \\
& /-\mathrm{w} / \leftrightarrow[- \text { Participant }] \\
& /-\mathrm{m} / \leftrightarrow \text { elsewhere. }
\end{aligned}
$$

\subsection{Implications for a theory of person features}

Having empirically established the importance of reference to 3rd person, we return to its theoretical implications. One of the most recent instantiations of the "3noP" view within an explicit representational proposal is the geometry of Harley and Ritter (2002):

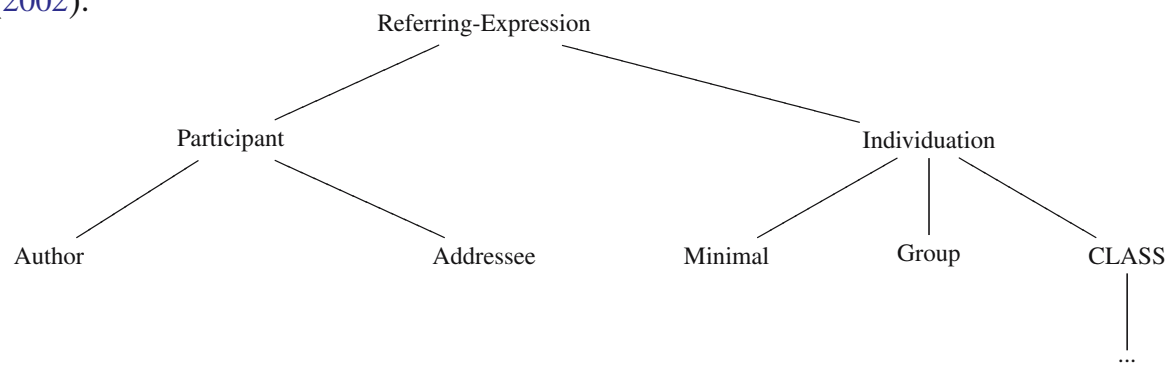


Harley and Ritter's geometry has been widely adopted due to the important formalization of implicational relations represented by the geometry: that dual number (represented by activation of both [Minimal] and [Group]) requires the presence of singular and plural in the number inventory, and that inclusive-we (represented by activation of both [Author] and [Addressee]) requires the presence of both 1st and 2nd person in the person inventory. These implicational relations and others of Greenberg's generalizations (e.g., that gender agreement implies number agreement) are captured by the structure of the geometry (where downward lines represent dominance relations which can essentially be traced upwards to form implicational statements). The geometry is one in which features are privative rather than binary, and hence, there is no explicit representation of the negative value of a feature. Thus, rather than a representation of 3rd person as, say, [-Participant], the geometry encodes this through literal absence of a Participant node. This representation of featural contrasts follows the "underspecification" approach to the unmarked member of a contrast, which is widely encountered in the phonological literature (e.g., Archangeli, 1984; Avery and Rice, 1989).

The representation of two adjacent 3rd persons in this sort of feature geometry (or in fact, any among the 3 noP view, although H\&R are the most explicit) is as in (40). Note that [Referring-Expression] is the feature that roots any pronominal or agreement node, and hence is not unique to 3rd person - in fact, the representation below, of two adjacent [Ref-Exp] nodes, will be present in every sequence of adjacent clitics.

H\&R Representation of two adjacent 3rd persons:

$$
\text { [Referring-Expression] [Referring-Expression] }
$$

The immediate question that thus arises is, how can one state a dissimilation rule (or a context-sensitive impoverishment rule) on (40) that will cause feature-alteration of the first clitic only when the second clitic is "3rd person"? ${ }^{12}$

\section{Contrastive visibility: phonological parallels}

In this section, I review a formally identical problem in another domain of the grammar: phonology. The problem of having to refer to seemingly underspecified values has reared its head before in the study of phonological representations. Much like in syntax, underspecification was pursued as an attempt to "make invisible" or render deficient those objects which behaved differently (Archangeli, 1984). However, immediate problems arose. Consider the plight of coronal underspecification: many researchers attempted to treat coronals as underspecified for place, due to their transparency in assimilation phenomena. However, Mohanan (1991), McCarthy and Taub (1992) and Steriade (1995) pointed out a number of problems for underspecification in phonology, exactly parallel to the dilemma above: while underspecification made a feature $\mathrm{F}$ invisible for process $\mathrm{X}$, it turns out that feature $\mathrm{F}$ is required to state the environment for some other process $\mathrm{Y}$. The solution to this problem came with Calabrese (1995), who proposed that it is not $\mathrm{F}$ which is underspecified, but X

12 A secondary issue which arises in this representational system is the question of how to distinguish 3 rd person from reflexives and impersonals. I return to this issue with a proposal and some suggestive evidence in Sect. 8. 
and $\mathrm{Y}$ which are relativized in their domain of visibility. More specifically, Calabrese proposed that rules may be parametrized to include reference to ALL VALUES, ONLY CONTRASTIVE VALUES, or ONLY MARKED VALUES. Calabrese's idea is that the invisibility of non-contrastive values on certain segments is part of the conditions of a particular rule, but not part of the inherent representation of those segments, since other rules may in fact have to refer to the presence of those values. Let us consider a case study, based on the behavior of Finnish vowels. Finnish has the inventory in (41), for both short and long vowels.

(41) Finnish inventory

$$
\begin{aligned}
& \text { [-back,-rd] [-back, +rd] [+back, }+ \text { rd }][+ \text { back, }- \text { rd }] \\
& \begin{array}{ccccc}
\mathrm{i} & \ddot{\mathrm{u}} & \mathrm{u} & & {[\text { +high, }- \text { low }]} \\
\mathrm{e} & \ddot{\mathrm{o}} & \mathrm{o} & & {[\text {-high, }- \text { low }]} \\
\ddot{\mathrm{a}} & & & \text { a } & {[\text {-high },+ \text { low }]}
\end{array}
\end{aligned}
$$

Finnish is famous for its vowel harmony, whereby suffixes must agree in $[ \pm$ back] with the root vowels (see, e.g., Ringen, 1975). However, a well-known exception is the transparency of [-low,-back,-round] vowels in harmony. Thus, in a word such as koti-na 'home-essive', the essive suffix takes the [+back] form -na (rather than -nä), because of the [+back] root vowel $o$ in the first syllable of the root. The high front vowel $i$ is ignored for the purposes of computing the harmonic value of the suffix. Based on (41), some researchers have proposed that /i/ is underspecified for [back] throughout the phonology, hence literally invisible at the point at which harmony applies. This solution achieves the goal of making all harmony essentially local, as the representation by hypothesis does not contain a [-back] value for $i$ until after harmony is computed.

A problem is caused by depriving/i/ of its [-back] feature, however: the well-known rule of Finnish assibilation (Kiparsky, 1973) turns a coronal stop into a fricative before $i$, as shown in (42). (This rule is subject to further conditions, as discussed extensively by Anttila (2003), who points out the important role of metrical conditioning.)
a. $\mathrm{t} \rightarrow \mathrm{s} /{ }_{-}[$-round,-back, +high $]$
b. /tilat-i/ 'order-PAST' $\rightarrow$ [tilasi]

It is difficult to make a case that assibilation occurs after vowel harmony; thus, judicious ordering of [-high] fill-in after harmony but before assibilation enjoys little support (and no generality as a solution to the problem of underspecification; see Steriade (1995) on other problems with ordering "fill-in" rules). The process in (42) can be understood as having a phonological basis in the fact that [+high, -back] vowels often cause palatalization and lenition of obstruents, in particular, $t$ to $s$, with president $\sim$ presidency as a well-known example of spirantization in English (Chomsky and Halle, 1968: 161), in addition to a host of other crosslinguistic examples, e.g., affrication of coronal stops before high front vowels in Brazilian Portuguese (Cagliari, 1997). In fact, Hall and Hamann (2006) characterize the high, front quality of /i/ as aerodynamically crucial in causing assibilation. However, if Finnish /i/ literally lacks [-back], assibilation cannot be characterized in these terms, because the conditioning feature is (by hypothesis) literally absent from the representation. Thus, while depriving /i/ of [-back] does work in making it invisible for harmony, such a representation leaves it puzzling why that same vowel should trigger assibilation. The proper solution, then, is one in which /i/ is fully specified for [-back] throughout the phonology, 
but different processes (e.g., harmony) are sensitive to what values of a feature will participate in the process. In this case, as /i/ is non-contrastive for the feature [back] (since there is no other [+high,-round] vowel in the inventory to distinguish it from by backness), one can understand Finnish suffixal harmonic alternations as restricted to conditioning by contrastive values of [back]; ${ }^{13}$ see Nevins (2004) for an application of this proposal to Finnish, based on Calabrese's original (1995) proposal that, given full specification of segments, syntagmatic processes may still be restricted/relativized in their access to certain values of a feature.

A similar case in which underspecification of a feature for one process leads to analytic problems in understanding a separate process which relies on that feature can be found in relation to "coronal underspecification" in English. Coronal underspecification was proposed to account for phenomena such as postlexical assimilation (e.g., hot cakes $\rightarrow$ hock kakes). But coronals must be referred to in early levels of phonology, to rule out e.g., *tl sequences, and to state a constraint on $j u$ nuclei in stressed syllables in American English (e.g., butte, mute, cute, 'tute, tune $\rightarrow$ [bjut, mjut, kjut, *tjut,*tjun]). Thus, whatever the correct understanding is of why coronals allow postlexical place assimilation, it is not to be found in depriving them of the feature [coronal] in their representation: this creates an ordering paradox. A possible solution within Calabrese's parametrized approach to feature values is that postlexical assimilation cannot alter marked values of [ \pm coronal] (by hypothesis, negative values of [coronal]), whereas morpheme structure constraints refer to all values of [coronal].

Thus, the *le lo meets me lui problem is, in some sense, familiar from other areas of the grammar: while it is tempting to underspecify a given grammatical object, e.g., 3rd person, in explaining its apparent exclusion from person agreement in Person Case configurations, it is nonetheless needed to condition a dissimilation rule in morphology. The proposed solution for 3rd person then, is to adopt Calabrese's model of parametrized visibility for person features in the syntax. One immediate consequence, however, of adopting this model is that person and number features must be binary (contra Harley and Ritter, 2002; see Trommer, 2006 for a similar conclusion), given any formulation of a definition of contrastiveness in a system without underspecification.

\section{Person features, representations, and definitions}

In this section, we move towards an alternative to the 3 noP view that will still allow for a syntactic and morphological distinction between 1st/2nd person on the one hand, and 3rd on the other. We discuss the binary features that compose person categories, and introduce the notion of relativization to all, marked, or contrastive values of these features. We will then set up the conditions on the operation Multiple Agree,

13 An interesting cognitive parallel arises in Sedivy, Tanenhaus, Chambers, and Carlson (1999) who made use of the real-time eye-tracking paradigm in an experiment with spoken language and visual contexts. Given a scene with a pink comb, a yellow comb, and a yellow bowl, subjects were given instructions such as Pick up the yellow comb. Sedivy et al. found that at the onset of the word yellow, subjects looked much faster and more frequently at the yellow comb, even before they had heard the head noun. The only logical explanation is that subjects understood that, given spoken instructions, their interlocutor would be more inclined to use the predicate yellow when it was contrastive for the object to be manipulated. That is, even though the predicate yellow was true of both the comb and the bowl, the subjects preferred to interpret it in a contrastive use. 
governing the realization of clitic sequences, that will be crucial in re-examining the typology of PCC effects once third person has a featural specification.

\subsection{Person representations}

Given the binary feature [ \pm Participant], where a positive value denotes that the referring expression contains one of the discourse participants, and the binary feature [ \pm Author], where a positive value denotes that the referring expression contains the author, person features will be represented as follows (I adopt these features from Halle (1997)):

$$
[-\mathrm{F}]=\neg[+\mathrm{F}]
$$

a. $[+$ Auth $]=$ the reference set contains the speaker

b. $[+$ Participant $]=$ the reference set contains one of the discourse participants.

a. $[+$ Auth,+ Part $]=1$ st person

b. $[-$ Auth, + Part $]=2$ nd person

c. $[-$ Auth, - Part $]=3$ rd person

d. $[+$ Auth, - Part $]=$ logically impossible .

These featural assignments represent the possibilities for natural language. [ \pm Participant] has been amply justified in the literature (Forchheimer, 1953:6); as an example, Harley and Ritter demonstrate that it expresses the fact that Maltese and Lyélé do not show gender distinctions in [+Participant]. The Basque g-/z-constraint discussed above makes crucial reference to [+Participant] as well. In Sect. 7, I discuss the use of $[ \pm$ Author] in comparison to a putative feature [ \pm Hearer].

However, not all languages have identical pronoun inventories. For languages that express a distinction between inclusive and exclusive 1st person (where inclusive means that the addressee is included and exclusive means that the addressee is not), I propose, following McGinnis (2005), that a language can add an additional specification: the unary feature [addressee]. ${ }^{14}$ Crucially, this feature need not be present in all pronominal/agreement inventories, as extensively argued by McGinnis; its presence on a [+Auth,+Part] feature-set, however, serves to indicate inclusive-"we". ${ }^{15}$ This feature will not interact in any of the PCC systems to be discussed. We return to this issue in Sect. 7.2.

One of the consequences of adopting [ \pm Auth] is the fact that the presence of [-Auth] within 3rd person may play an active role in the grammar (e.g., when syncretisms arise between 2nd and 3rd person); hence I maintain here that the feature is always specified. When there is always full specification for binary features, as I am adopting here, there is an important distinction to establish: one that I will argue becomes relevant for certain aspects of the syntactic computation. It is whether or not a particular feature is contrastive within a given set of other features.

\footnotetext{
14 Arguments for a theory of number features in which most features are binary but additional subdistinctions are accomplished by a unary feature can be found in Harbour (2003a).

15 Although logically redundant, unary [addressee] may be added to a [-Auth,+Part] feature set, yielding a featural basis for syncretism effects found in many Algonquian languages and in Kiowa, Acehnese, and Diola-Fogny in which (semi-)identical forms express both inclusive-1pl and 2nd person, which would share [+Part] and [addressee].
} 
(45) A pronoun $\mathrm{S}$ with specification $\alpha \mathrm{F}$ is contrastive for $\mathrm{F}$ if there is another pronoun $\mathrm{S}^{\prime}$ in the inventory that is featurally identical to $\mathrm{S}$, except that it is $-\alpha \mathrm{F}$.

Or, alternatively (and equivalently): ${ }^{16}$

(46) An instance of the feature $\mathrm{F}$ is contrastive within a set of other features $\mathrm{S}$ if both values of $\mathrm{F}$ may occur in $\mathrm{S}$.

The notion of contrastiveness is paradigmatically based (i.e. on static properties of the inventory), but what is interesting about its application here is that it will be directly used in syntagmatic configurations (i.e. where more than one person feature interacts in a structured representation).

One of the direct consequences of this definition is that [ \pm Auth] is not contrastive within the feature bundle [-Part,-Auth] (since there is no pronoun specified [-Part, + Auth]). That is to say, [ \pm Auth] is not contrastive when it co-occurs with [-Part]. On the other hand, [ \pm Auth] is contrastive when it co-occurs with [+Part], since both values $[+$ Auth] and [-Auth] can occur in the presence of [+Part].

It should be mentioned here that whether or not a phi-feature like [ \pm Auth] is contrastive or not represents a departure from common practice in feature-driven models of agreement (e.g., Chomsky, 2001). In fact, it may appear that whether a given feature is contrastive or not looks like a "feature of a feature" or a "meta-feature". I would argue that it is true that contrastiveness is a property of a given feature within the context of other features with which it co-occurs. Clearly, reference to such a property represents an addition to the standard minimalist assumptions about features. The question is whether the empirical coverage it affords justifies its addition to syntactic theory, which is what I hope to convince the reader of.

It should also be noted that by adopting a binary-valued (as opposed to privative) feature system, markedness is not read off by structural complexity. For each binary feature, it must be indicated which value of the feature is the marked one. There are a variety of diagnostics for what makes a given value of a feature marked. One of these is that syncretisms for other features tend to occur more in the marked category; for example, as noted by Noyer (1992), gender features are often impoverished in the context of [+Auth] but not [-Auth], e.g., in Semitic; similarly, for Germanic and Romance, gender features are impoverished in the context of [+Part] but not [-Part]. Another source of evidence comes from conjoined noun phrases in which each conjunct contains a different binary value; in these cases, verbal agreement for person is inevitably with the marked category, e.g., when "he" and "I" are conjoined, the result is $[+$ Auth $]$ agreement on the verb. For the person features we are considering here, the following markedness statements hold:
a. + is the marked value of [Part]
b. + is the marked value of [Auth]

\subsection{Value-relativized parametrization}

The key idea to be adopted here is that certain syntagmatic processes may be restricted in their access to all values of a given feature. Calabrese's proposal for phonological processes such as vowel harmony, which across languages seem to have differing

16 Note that both of these formulations depart from Calabrese's definition, which is stated in terms of deactivated filters. 
locality conditions and to involve different sets of participating segments, was that the core grammatical principle was the same, but that the search for a feature may be restricted to, for example, only contrastive values of a feature:

(48) For a feature F, a search may be relativized to a domain which includes all values of $\mathrm{F}$, only the contrastive values of $\mathrm{F}$, or only the marked values of $\mathrm{F}$.

This parametric variation in which values of a feature are included in a search turns out to be very useful in understanding microvariation between languages that have the same inventories, but different items that participate in a given grammatical process. Within this paper, I will extend the general approach to cases of microvariation within Person-Case effects in clitic clusters.

\subsection{Conditions on Multiple Agree}

The general approach that I will take to person-case effects is that they arise when both pronouns/clitics are within the same agreement domain. I will adopt the insight of Anagnostopoulou (2005), Bejar and Rezac (2003), and Adger and Harbour (2006) that the PCC is a result of two DPs within the domain of a single probing head. Thus, within the framework for agreement proposed in Chomsky (2001) and subsequently refined by Hiraiwa (2001, 2004), (Multiple) Agree is a featural relation between a Probe and a set of one or more Goals.

I have chosen to implement the analysis here in terms of Multiple Agree by a single head, rather than in terms of a general condition on person in terms of case hierarchies or grammatical function, because the PCC only arises in the ditransitive domain, between indirect and direct object, and not between, say, subject and object. Thus, while the PCC banning a 3rd dative above a 1/2 accusative when both are clitics holds throughout Italian dialects, there are dialects in which the PCC holds between IO and DO clitics but not between subject and object clitics. Such a case is cited by Bianchi (2005), based on a personal communication from Cecilia Poletto on the Northern Italian dialect of Loreo (Rovigo), which has subject clitics, but nonetheless allows a 3-1 combination of subject-object clitics:

Lu el me ga invidá
He 3sg.subj-cl 1sg.obj-cl has-3sg invited

He has invited me.

(Loreo; Bianchi, 2005:8)

In no version of Agree-based syntactic theory do subject and object occupy the same domain at the point of the relevant Agree operations, ${ }^{17}$ so if PCC effects are modeled in terms of Multiple Agree, it is unsurprising that no PCC effects will hold between subject and object clitics. There is robust evidence, on the other hand, that indirect and direct object constitute two arguments within the same domain. For example, Bruening (2001) argues that scope-freezing in ditransitive constructions is due to a Tucking-In condition on QR as both of these arguments must target the same head. The reader is referred to Anagnostopoulou (2003) for an extensive discussion of the syntax of ditransitive constructions in which IO and DO constitute arguments in the same domain.

In adopting Multiple Agree, then, I am assuming that the relevant probe is $v$, or perhaps a complex head formed by $v$ and an Applicative head that mediates ditransitive argument structure. In the subsequent discussion, then, when I refer to the Probe

\footnotetext{
17 I assume that movement operations such as object shift are ordered after the relevant Agree operations for phi-features have taken place.

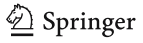


specified to Multiple Agree with arguments in its domain, I am referring to $v$. The result of this Multiple Agree operation will be the clitics that are realized in conjunction with the verb. Following Borer (1984), I will assume that clitics are the direct spell-out of agreement between a verb and its argument(s). Under this view, (il)licit clitic combinations provide a direct window onto the Agree mechanisms occurring between $v$ and the arguments within its domain.

The following two conditions on Multiple Agree will be crucial to the account. These are inspired by Anagnostopoulou (2005) and Hiraiwa (2001, 2004), but formalized differently here. The first pertains to locality within an agreement domain: once the visibility parameter is set for a given domain, the highest argument within that domain must fall within the scope of that visibility parametrization. The second pertains to featural identity for elements within that domain: they must match in value with each other. Both of these conditions are crucial to the present understanding of the PCC.

Contiguous Agree: For a relativization $\mathrm{R}$ of a feature $\mathrm{F}$ on a Probe $\mathrm{P}$, and $\mathrm{x} \in$ Domain $(\mathrm{R}(\mathrm{F}))$,

$\neg \exists \mathrm{y}$, such that $\mathrm{y}>\mathrm{x}$ and $\mathrm{P}>\mathrm{y}$ and $\mathrm{y} \notin \operatorname{Domain}(\mathrm{R}(\mathrm{F}))$

"There can be no interveners between $\mathrm{P}$ and $\mathrm{x}$ that are not in the domain of relativization that includes $\mathrm{x}$ ".

(51) Matched Values: For a relativization $\mathrm{R}$ of a feature $\mathrm{F}, \exists \alpha, \alpha \in\{+,-\}$,

$\forall \mathrm{x}, \mathrm{x} \in \operatorname{Domain}(\mathrm{R}(\mathrm{F})), \operatorname{val}(\mathrm{x}, \mathrm{F})=\alpha$

"All elements within the domain of relativization must contain the same value for the feature $\mathrm{F}$ being agreed with".

These conditions are inviolable and not ranked; they must be met in every language. Although Multiple Agree was proposed as a dynamic operation in a derivational syntax, it is important to point out that these two conditions are compatible with a representational set of conditions on agreement. If they are to be understood as derivational constraints on the single operation of Multiple Agree, it is important that Agreement with the two goals exists simultaneously, as originally formulated in Hiraiwa's proposal. ${ }^{18}$

18 A reviewer suggests that these conditions on a simultaneous agreement operation might instead be replaced by a sequence of two distinct Agree operations. The reviewer proposes, for example, that the Strong PCC ban on a [+Participant] indirect object above a [+Participant] direct object results from an intervention effect during an attempt at Agree with the direct object. In effect, $v$ Probes down and finds the indirect object, without a problem. Then, a second, distinct Agree applies, in which $v$ seeks to agree with the direct object. However, the c-commanding indirect object intervenes, thereby blocking Second-Agree between $v$ and the direct object.

This is a fascinating suggestion, but it must ultimately be rejected. First, it would require a radical reanalysis of many other phenomena, such as multiple wh-questions. Essentially, the suggestion is that the Strong PCC arises from the fact that the first argument blocks Agree with the second argument. In other words, the suggestion is that there is no Multiple Agree in the Parallel/Simultaneous sense, there is only Agree, which may probe more than once (henceforth, First-Agree and Second-Agree). Note that the mechanics of this suggestion will rule out any case of Multiple-Wh where the two whs are in situ, for the exact same reason that its mechanics are intended to rule out multiple goals with [+Participant]. Moreover, Rackowski and Richards (2005) present extensive evidence from Tagalog that a mechanism of Second-Agree is not blocked by the goal that underwent First-Agree.

The existence of Multiple Wh-movement thus presents an immediate problem for the idea that PCC effects result from a general locality condition on Second-Agree. 


\section{Varieties of PCC}

In this section I explore a variety of person-case effects that have been investigated throughout the literature. Bonet (1991) and Anagnostopoulou (2005) discuss the "weak" and "strong" versions of the PCC, which involve different constraints on licit clitic combinations. ${ }^{19}$ I will differ in my analytic approach here, however, in that the crucial aim is to adopt the same syntactic mechanism (namely, the conditions on Multiple Agree in (50) and (51)) in understanding both the weak and strong PCC, as well as the Me-First PCC (which will be introduced below):

Desideratum: All versions of the PCC should be explained by the same syntactic mechanism, differing only in relativization to which (values of which) features must obey the constraint.

Footnote 18 continued

One possibility in order to rule out PCC effects but correctly allow Multiple Wh-phrases would be that the "Second-Agree only converges if the First Goal moves" hypothesis is only relevant for A-type agreement. The most promising place to look for relevant evidence would be in Icelandic Dat-Nom constructions. Note that on the Multiple-Agree account that I have developed in this paper (with the Matched-Value constraint), the contrast between the single question-mark of (i) and the double question-mark of (ii) (15b \& 16b in Holmberg and Hróarsdóttir (2004)) can be understood:

(i) ?Hvapa studentum finnast tölvurnar ljótar

Which student-PL finds-PL computers-PL ugly

Which students find the computers ugly?

(ii) ??Hvapa student finnast tölvurnar ljótar

Which student-SG finds-PL computers-PL ugly

Which student finds the computers ugly?

In the Multiple-Agree with Matched-Values framework, of course (i) should be better than (ii), since both Goals are Plural, whereas (ii) should be bad, because one Goal is singular, while the other is Plural. The reviewer's "Second-Agree only converges if the First Goal moves" hypothesis cannot explain these data, since the First Goal indeed has moved (undergoing $w h$-movement), and since the alternative developed in the review explicitly rejects the Matched-Value constraint. (Note that this only matters if we want to cover the contrast between one and two question marks for the configurations in Holmberg and Hróarsdóttir (2004)).

An additional area in which we might look for relevant data is the Multiple-Nominative constructions in Japanese. Miyagawa (2001) reports that in a Multiple Nominative construction, interestingly enough, both DPs seem to need to move. This holds true even in OSV orders, where the scope of the subject outside negation can be taken to show that the subject DP has also moved overtly:

(i) siken-ga zen'iin-ga uke-rare-nakatta

exam-nom all-nom take-able-neg-pst

The exam, all could not take it. $(\forall>\neg)$

(S. Miyagawa. pers. comm. November 2005)

The fact that both DPs must move in a Multiple-Nom construction would make sense under a MultipleAgree type view: if both DPs are agreed with simultaneously, then an EPP-tied-to Agree driving overt movement would presumably only have the option of moving both. In the reviewer's implementation, there is no way to enforce this.

To conclude, there are three lines of data (Multiple-Wh, Icelandic Dat-Nom constructions, Multiple-Nom) that introduce complications for the reviewer's suggestion that syntax includes an option of "Double-Agree". I have chosen to formalize the analysis within Multiple Agree in the text, as that model has been applied to a number of other syntactic phenomena and does not encounter the above empirical difficulties.

19 There are other researchers who have worked on the PCC, often restricting their attention to the weak PCC, where the 3 noP view is employed in the implementation; clearly the 3 noP view, in addition to its empirical shortcomings described here, is of little avail in understanding strong and Me-First PCC effects. 
The first constraint to be examined is the "me lui" version, so named because, in French, it amounts to a prohibition on the clitic sequence me lui (1-acc 3-dat), where it is assumed that these clitics double an underlying argument structure where the indirect object c-commands the direct object. This is also called the "Weak PCC". It effectively bans configurations of the form: *3 1 and *32, where linear order here reflects underlying dominance relations. In other words, a [-Participant] dative cannot dominate a [+Participant] accusative within the same domain. Consider the following examples from Catalan:
*A en Josep, me li va recomenar la Mireia to the Josep, 1st-acc 3rd-dat recommended the Mireia She (Mireia) recommended me to him (Josep).

(Catalan; Bonet, 1991:178)
*A en Josep, te li va recomenar la Mireia to the Josep, 2nd-acc 3rd-dat recommended the Mireia She (Mireia) recommended you to him (Josep).

(Catalan; Bonet, 1991:179)
En Josep, te '1 va recomenar la Mireia the Joseph, 2nd-dat 3rd-acc recommended the Mireia She (Mireia) recommended him (Josep) to you.

(Catalan; Bonet, 1991:179)

Incidentally, the contrast in (53)-(54) cannot be handled by claiming that 3rd person is not a person, for reasons internal to Catalan. Bonet (1991: 209) points out that (53) is grammatical when the dative clitic is replaced by the locative clitic:
A en Pere, m'hi
va recomenar la Mireia
to the Pere, 1 st.acc+loc. recommended the Mireia
Mireia recommended me to him (Pere).

(Catalan; Bonet, 1991:209)

Interestingly, such a strategy can only be pursued in clitic left-dislocation environments, and cannot rescue a clitic-doubling structure:

$$
\begin{aligned}
& \text { *M'hi ha presentat a la Maria } \\
& \text { 1st.acc+loc introduced to the Maria } \\
& \text { S/he has introduced me to Maria. }
\end{aligned}
$$

(Catalan; Bonet, 1991:212)

This strongly suggests a syntactic analysis in which the locative $h i$ can be generated to resume a left-dislocated goal, under a "feature compatibility" requirement for coindexation (Bonet, 1991:213). If this account is on the right track, it shows that a locative clitic does not participate at all in Multiple Agree (similarly to the invisibility of prepositional phrases to the phi-feature system). This contrast between locative $h i$ and 3rd-person $l i$ is further suggestive of the fact that 3rd-person must have a representation that is distinct from "no person". 20

Next, we examine the "Strong PCC", which bans all of the configurations of the weak PCC above, as well as additionally excluding configurations in which there are two [+Participant] arguments in the same domain that bear different values for the

20 Eulàlia Bonet brought this argument to my attention. 
feature [Author]. In other words, in addition to the ban on *32 and $* 31$ from the weak PCC, in the strong PCC, the additional excluded person-case combinations are: *12 and $* 21$ within the same domain, where linear order reflects underlying dominance relations.

*O Kostas mu se sístise the Kostas 1st-dat 2nd-acc introduced Kostas introduced you to me.

(Greek; Bonet, 1991: 178)
*O Kostas su me sístise
the Kostas 2nd-dat 1-acc introduced
Kostas introduced me to you.

(Greek; Bonet, 1991: 178)

Finally, we turn to the Me-First PCC, which is intermediate in restrictiveness between the weak and strong PCC, and less widely encountered than either. This version of the PCC disallows configurations in which a [-Auth] argument dominates a [+Auth] argument; in other words, if there is a first person argument, it must be first in the domain (hence the name "Me-First"). However, unlike the strong PCC, the Me-First PCC admits configurations of the form 12 . Summarizing, the Me-First PCC specifically excludes person-case combinations of the form *2 1 (as well as *31), where linear order reflects underlying dominance relations.

$$
\begin{aligned}
& \text { *Me te escapé } \\
& \text { 1-refl 2-dat escaped-1.pst } \\
& \text { I escaped from you. }
\end{aligned}
$$

(Spanish (some speakers); Perlmutter, 1971:26)

(61) $\mathrm{Te}$ me escapaste 2-refl 1-dat escaped-2.pst You escaped from me.

(Spanish (some speakers); Perlmutter, 1971:25)

Some versions of the Me-First PCC only disallow *3 1 and *21, while allowing $3>2$; see for example the discussion of Romanian below. Other versions additionally ban weak PCC configurations, in which a [-Part] argument may not dominate a [+Part] argument; see the discussion of Classical Arabic below, and Spanish for the above speakers (see Fernández-Soriano, 1999, p. 1927).

Turning to a syntactic account of these PCC effects, I will adopt Anagnostopoulou's (2005) idea that the strong and weak (and, I claim, the Me-First) PCC all arise in the same configuration: when two weak DPs are in the domain of the same head. An interesting challenge here is to understand and explain how there can be so much microvariation reported for dialects of Spanish/Catalan; in the words of Bonet (1991:179): "The judgments concerning combinations of first and second person clitics vary considerably from speaker to speaker." Ideally, this microvariation is best understood in terms of a very small microparameter on the head that facilitates such configurations (and not in terms of the way "1st person" is represented in the language as a whole).

The crucial idea that I will adopt here is that the locus of variation is in the search domain as set by the Probing head in charge of agreement within this domain (the proposal here is consistent with this head being identified either as $v$ or Appl, and no commitment is made here). I will thus adopt an idea that is inspired by Bejar (2003): variation in the agreement "preferences" of a given multi-argument configuration are due to the featural requirements for agreement set by the Probe. 
Thus, rather than viewing PCC effects as arising from the nature of the representations specified on arguments (e.g., "3rd person datives have no person feature in Spanish"), what I will pursue here is the idea that the variation and "strength" of PCC depends on how many values are excluded by the relativization domain as set on the agreeing head that controls the domain.

Once the parametric choice of value-relativization of the domain is chosen, the conditions on an Extended Agree domain (with no interruptions/interveners in the domain) and on Matched Values (with agreeing values for the chosen feature) must be met. They are repeated below.

(62) Contiguous Agree (CA): For a relativization $\mathrm{R}$ of a feature F on a Probe P, and $\mathrm{x} \in \operatorname{Domain}(\mathrm{R}(\mathrm{F}))$,

$\neg \exists \mathrm{y}$, such that $\mathrm{y}>\mathrm{x}$ and $\mathrm{p}>\mathrm{y}$ and $\mathrm{y} \notin \operatorname{Domain}(\mathrm{R}(\mathrm{F}))$

"There can be no interveners between $\mathrm{P}$ and $\mathrm{x}$ that are not in the domain of relativization that includes $\mathrm{x}$ "

(63) Matched Values (MV): For a relativization $\mathrm{R}$ of a feature $\mathrm{F}, \exists \alpha, \alpha \in\{+,-\}$,

$\forall \mathrm{x}, \mathrm{x} \in \operatorname{Domain}(\mathrm{R}(\mathrm{F})), \operatorname{val}(\mathrm{x}, \mathrm{F})=\alpha$

"All elements within the domain of relativization must contain the same value".

Let us proceed to see how varying relativizations of the search domain will yield the varieties of the PCC.

\subsection{Deriving the weak PCC}

In the first scenario to consider, the search has been relativized to the marked values of [Participant], i.e., positive values, as in (47). For a convergent derivation to occur, therefore, the following condition must be met (CA): there cannot be any unmarked values of [Participant] that intervene between the Probe and elements with the featural specifications it is looking for. Note that the second condition, MV, is trivially met when there is marked relativization to a single value of a binary feature (i.e., in this case), as there cannot be elements within this domain that have differing values for the feature in question. The possibilities for clitic ordering (with left-to-right indicating dominance, i.e. dative on the left and accusative on the right) are given below, and, in each case, an ' $x$ ' indicates that the configuration fails to meet a condition on Multiple Agree. ${ }^{21}$ Checkmarks $(\checkmark)$ will be used in the table to indicate convergent derivations.

(64) Weak PCC: If Acc is 1/2, then Dat is $1 / 2$.

Probe's Value-Relativization: Marked [Part].

\begin{tabular}{llll} 
& & CA & MV \\
\hline$\checkmark$ & 13 & & \\
$\checkmark$ & 12 & & \\
$\checkmark$ & 21 & & \\
$\checkmark$ & 23 & & \\
& 31 & X & \\
& 32 & X &
\end{tabular}

21 This is purely for presentational purposes; readers who see an affinity with optimality-theoretic tableaus are reminded that these conditions are inviolable and unranked. 
To summarize the intuition behind the weak PCC within the current syntactic implementation: the Probe is searching for Marked values of Participant. Configurations such as $<31>$ and $<32>$ constitute violations of the Contiguous Agree domain, because a non-marked value of [Participant] interrupts the Agreement span. Independent of the particular implementation in terms of Multiple Agree given here, the general logic behind the claim is that given the feature [Participant], a marked value of this feature cannot be only on the lower argument within the domain of the $v \mathrm{P}$.

\subsection{Deriving the strong PCC}

We turning now to the strong PCC, deriving this constraint from the same principles as the weak PCC above, with the difference only in the relativization of featurevalues on the Probe. The strong PCC results from a Probe that is specifically looking for contrastive values of [Author]. Recall from the definition of contrastiveness given in (45) that [Author] is not contrastive in the context of [-Part], i.e., in 3rd persons. Given this relativization on the Probe, the condition on Continuous Agree will be contravened when a non-contrastive value of [Auth] intervenes in the agreement span, i.e., when a 3rd person dominates a 1st or 2nd person in the domain. Moreover, given this relativization, as Multiple Agree can potentially apply within combinations of 1st and 2nd person, the condition on Matched Values for Multiple Agree will lead to an illicit derivation when there are conflicting contrastive values for [Auth], i.e., $[+$ Part, + Auth $]$ and $[+$ Part, - Auth]. The possibilities for clitic ordering (with leftto-right indicating dominance, i.e. dative on the left and accusative on the right) are given below.

(65) Strong PCC: Acc must be 3rd.

Relativization: Contrastive [Auth]

\begin{tabular}{|c|c|c|c|}
\hline & $\mathrm{CA}$ & MV \\
\hline \multicolumn{2}{|c|}{$\begin{array}{ll} & \\
\checkmark \quad 13\end{array}$} & & \\
\hline & 12 & & $\mathrm{x}$ \\
\hline & 21 & & $\mathrm{x}$ \\
\hline$\checkmark$ & 23 & & \\
\hline & 31 & $\mathrm{x}$ & \\
\hline & 32 & $\mathrm{x}$ & \\
\hline
\end{tabular}

Summarizing the strong PCC intuition, since the Probe is searching for contrastive values of [Auth], configurations such as $<31>$ and $<32>$ constitute violations of the Contiguous Agree domain, because a non-contrastive value of [Auth] interrupts the Agreement span, while configurations of 1 and 2 constitute violations of the Matched Value condition. Independent of the particular implementation in terms of Multiple Agree given here, the general logic behind the analysis of the Strong PCC here is that given contrastive values of [Author], there cannot be distinct values of this feature within the domain of the $v \mathrm{P}$.

\subsection{Deriving the Me-First PCC}

Finally, we turn what I have identified as the Me-First PCC, which has received little analytical attention in the literature. The constraint is that if Dat is $2 / 3$, Acc cannot be 1st person. This constraint arises when there is a relativization on the Probe to agree 
with marked values of [Author], which are the positive values according to 5.1. For a convergent derivation to occur, therefore, the following condition must be met (CA): there cannot be any unmarked values of [Author] that intervene between the Probe and elements within the featural specifications it is looking for. Note that the second condition, $\mathrm{MV}$, is trivially met when there is marked relativization to a single value of a binary feature (i.e., in this case), as there cannot be elements within this domain that have differing values for the feature in question. The possibilities for clitic ordering (with left-to-right indicating dominance, i.e., dative on the left and accusative on the right) are given below.

(66) Me-First PCC. Relativization: Marked [Auth].

\begin{tabular}{|c|c|c|c|}
\hline & & CA & MV \\
\hline$\checkmark$ & 13 & & \\
\hline$\checkmark$ & 12 & & \\
\hline & 21 & $\mathrm{x}$ & \\
\hline$\checkmark$ & 23 & & \\
\hline & 31 & $\mathrm{x}$ & \\
\hline$\checkmark$ & 32 & & \\
\hline
\end{tabular}

To summarize the Me-First PCC intuition, the Probe is searching for marked values of Auth. Configurations such as $<31>$ and $<21>$ constitute violations of the Contiguous Agree domain, because a non-marked value of [Auth] interrupts the Agreement span. Independent of the particular implementation in terms of Multiple Agree given here, the general logic behind the claim is that given the feature [Auth], a marked value of this feature cannot be only on the lower argument within the domain of the $v \mathrm{P}$.

There is an important note to add here. The relativization to marked [Auth] does not rule out the configuration $<32>$, since both of these are [-Auth]. This is a welcome result, as $<32>$ is allowed in Romanian (Ciucivara, 2004, Farkas and Kazazis, 1980):

(67) Maria i- te- a prezentat

Maria 3-dat 2-acc has introduced

Maria $_{m}$ has introduced you to her .

(68) Maria me- te- a prezentat

Maria 1-dat 2-acc has introduced

Maria has introduced you to me.

(69) *Maria i- m- a prezentat

Maria 3-dat 1-acc has introduced

Maria $_{m}$ has introduced me to her $z$.

(70) *Maria tie- m- a prezentat

Maria 2-dat 1-acc has introduced

Maria has introduced me to you.

\subsection{Deriving the ultrastrong PCC}

In addition to the Me-First effects noted above for Romanian, for some speakers of Spanish (see Perlmutter, 1971: p. 26) and also for Classical Arabic, ${ }^{22}$ in addition to the

22 As reported in Bonet (1991, note 8, p. 184). 
Me-First effects ruling out $<31>$ and $<21>$, the combination $<32>$ is also banned. The "ultrastrong PCC" is thus a combination of the Me-First PCC together with the weak PCC.

The following pattern in Classical Arabic is reported by Abdelkader Fassi-Fehri (pers. comm., November 2005; see Fassi-Fehri, 1988: 116 for the starred examples as part of his proposal for a Person Constraint that demands $1>2>3$ ):

(71) * $a^{c}$ ṭa:-ka-ni:

gave.3subj-2dat-1acc

He gave me to you. $*<21>$

(72) *?a ${ }^{c}$ tay-ta-hu:-ni:

gave-2subj-3dat-1acc

You gave me to him. * $<31>$

(73) * $\mathrm{a}^{\mathrm{c}}$ tay-tu-hu:-ka:

gave-1subj-3dat-2acc

I gave you to him. $*<32>$

(74) Pa $^{c}$ ta-ni:-ka

gave.3subj-1dat-2acc

He gave you to me. $<12>$

(75) $P a^{c}$ tay-ta-ni:-hi:

gave-2subj-1dat-3acc

You gave him to me. $<13>$

(76) $2 a^{c}$ tay-tu-ka-hi:

gave-1subj-2dat-3acc

I gave him to you. $<23>$

This contains the Me-First pattern of Romanian, but unlike Romanian, Classical Arabic contains a Weak PCC banning $<32>$ in addition. I will call this an "Ultrastrong PCC" as it requires that the Probe contain an additional relativization of Marked [Participant], as in the weak PCC cases shown in (64), which adds the restrictions afforded by the weak PCC. Note that this is a welcome result: the Me-First $+{ }^{*}<3$ $2>$ PCC requires two separate relativizations, one for marked [Author] and one for marked [Participant], and this may help explain its relative rarity.

This constraint arises when there is a relativization on the Probe to agree with marked values of [Author] and with marked values of [Participant], which are the positive values according to (47). For a convergent derivation to occur, therefore, the following condition must be met (CA): there cannot be any unmarked values of [Author] nor can there be any unmarked values of [Participant] that intervene between the Probe and elements within the featural specifications it is looking for. The possibilities for clitic ordering (with left-to-right indicating dominance, i.e., dative on the left and accusative on the right) are given below, and, in each case, an ' $x$ ' indicates that the configuration fails to meet a condition on Multiple Agree. The parenthesized value next to the ' $x$ ' indicates which unmarked feature [Auth] or [Part] has incurred an intervention yielding a locality violation. 
(77) Ultrastrong PCC. Relativization: Marked [Auth], and Marked [Part].

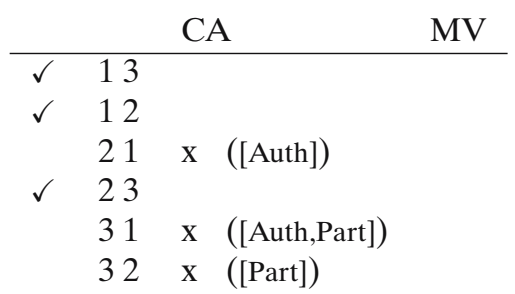

To summarize the Ultrastrong PCC intuition, the Probe is searching for marked values of Auth and Participant. Configurations such as $<31>$ and $<21>$ constitute violations of the Contiguous Agree domain, because a non-marked value of [Auth] interrupts the Agreement span. Configurations such as $<31>$ and $<32>$ constitute violations of the Contiguous Agree domain, because a non-marked value of [Part] interrupts the Agreement span. Independent of the particular implementation in terms of Multiple Agree given here, the general logic behind the analysis of the Ultrastrong PCC given here is that given the features [Auth] and [Part], a marked value of either of these features cannot be on only the lower argument within the domain of the $v \mathrm{P}$.

\subsection{Considering the typology of PCC effects}

We can thus reconsider the typology of PCC effects according to the parametric options of all, contrastive, and marked values of $\{[ \pm$ Part $],[ \pm$ Auth $]\}$. Relativization to all values is the most permissive, and a language in which the probe allows all values of both $[ \pm$ Part] and $[ \pm$ Auth] has no PCC effects. Relativization to marked values is more restrictive than relativization to contrastive values, as it admits fewer potential arguments in the agreement domain. Finally, in considering the "weak" versus "strong" PCC, we may conclude that a Probe relativization of [Auth] is more restrictive ("stronger") than a relativization of [Part].

The various combinatorial possibilities of parametric visibility specifications of [Participant] and [Author] on the Probe are shown in the following table.

(78) Combinatorial possibilities yielding a PCC typology

\begin{tabular}{|c|c|c|c|}
\hline & All [Auth] & Contrastive [Auth] & Marked [Auth] \\
\hline All [Part] & No PCC & Strong PCC & $\begin{array}{c}\text { Me-First with }<32> \\
\text { ok (Romanian) }\end{array}$ \\
\hline Contrastive [Part] & "Me-Last" & Logically Impossible & Logically Impossible \\
\hline Marked [Part] & Weak PCC & Strong PCC & $\begin{array}{l}\text { Ultrastrong PCC } \\
\text { (Classical Arabic) }\end{array}$ \\
\hline
\end{tabular}

A brief comment will be made here on the appearance of strong PCC twice in the table. Note that in (65), we formulated a relativization to Contrastive [Author] as responsible for the Strong PCC. The effect of including an additional relativization to Marked [Part] will yield no further restrictions.

There is one more aspect of the typology that requires discussion. It appears that the set of possible relativizations within the languages we are considering might not include contrastive values of [Participant], for the following reasons. A relativization 
to contrastive [Participant] would thus exclude 1st person from the Probe's agreement possibilities. This relativization is logically incompatible with marked [Author], as this specification requires 1st person agreement, so the combination of contrastive [Part] and marked [Auth] is excluded, as it will result in no possible convergent derivations.

Consider the combination of contrastive [Part] with contrastive [Auth]. By the CA condition, this will rule out any 3-first (not contrastive for [Auth]) and any 1-first (not contrastive for [Part]) clitic combinations. By the MV condition, this will rule out $<21>$ and $<23>$ combinations, as the former will disagree in contrastive values for [Auth] and the latter will disagree in contrastive values for [Part].

Contrastive [Part] and Contrastive [Auth]

\begin{tabular}{lll} 
& CA & MV \\
\hline 13 & $\mathrm{x}$ & \\
12 & $\mathrm{x}$ & \\
21 & & $\mathrm{x}$ \\
23 & & $\mathrm{x}$ \\
31 & $\mathrm{x}$ & \\
32 & $\mathrm{x}$ &
\end{tabular}

This combination thus also yields no convergent derivations, so is marked as Logically Impossible.

Finally, consider contrastive [Part] on its own, with all values of [Auth] visible. This will only allow the clitic sequences $<21>$ and $<31>$. I will call this system a "me-last" system: if there is a direct object, then it must be 1st person; and if there is a 1st person, it must be the direct object. This system is unattested at present, but predicted to exist (though admittedly, it does seem a bit strange).

To summarize the typological possibilities, the two person features we have considered here, and the three relativization possibilities, yield all of the attested range of PCC effects, ${ }^{23}$ and seem perhaps to overgenerate mildly in predicting one additional, as yet unattested case of PCC effects.

\subsection{Unattested but logically possible PCC effects}

In this subsection we consider three logically possible but unattested PCC effects, and show how they are impossible to capture in the featural system developed here.

First, recall that there is a Me-First PCC, which requires that [+Auth] accusative cannot be dominated by [-Auth] dative, thus banning the configurations $<31>$ and $<21>$ (while still allowing $<32>$ in the case of Romanian). From a descriptive standpoint, it is logically possible that there should be a "You-first" PCC:

(80) You-First PCC: A second person accusative cannot be dominated by a non-second person dative, e.g.: $*<32>$, $*<12>$, but $<31>$ is permissible.

Such a system is unattested and predicted to be impossible here. The reason that a You-First PCC could not exist is because, given our features, there is no way to refer to 2 nd person alone. The only person features are [ \pm Auth] and $[ \pm$ Part], and the

23 Though my exemplification of these phenomena are mostly confined to Indo-European and Arabic, the PCC is typologically attested in a very wide range of languages; I refer the reader to Bonet (1991), who discusses the Strong PCC in Basque and Georgian, and to the sources I discuss in Sect. 7.2 on PCC effects in Yimas, Warlpiri and Passamaquoddy. 
only value-relativized parameterizations are to Marked, Contrastive, or All values of one of these features. While Me-First effects can be derived because 1st person is Marked [Auth], putative You-First effects cannot be derived because there is no Marked feature value that corresponds exclusively to 2 nd person.

Second, recall that there is the weak PCC, which requires that a $[+$ Part $]$ accusative cannot be dominated by a [-Part] dative, thus banning the configurations $<31>$ and $<32>$. The Weak PCC essentially bans a 3rd dative whenever the accusative is non-3rd:

(81) Weak PCC: No 3rd dative when accusative is not 3rd, e.g., $*<31>$ and $*<32>$ but $<21>$ and $<12>$ permissible.

It is thus logically possible that there could be a PCC that ruled out 1st person datives when the accusative is non-1st, called the "Me \& Nobody PCC".

(82) Me\&Nobody PCC: No 1st dative when accusative is not 1st, e.g.: *<1 $2>$ and $*<13>$ but $<32>$ and $<23>$ permissible.

The Weak PCC is derived in the present system due to relativization to marked [+Participant]. The value [+Participant] groups together 1st and 2 nd person as a natural class sharing a marked feature, and the weak PCC disallows the persons sharing this marked feature from being dominated by an argument that does not bear this marked feature. There is no way to derive the Me \& Nobody PCC in (10) in our feature system, because there 2 nd person and 3 rd person do not constitute a natural class that shares a marked feature.

Finally, recall that there is a Strong PCC, which bans $*<12>$ and $*<21>$ because they differ in their value for the contrastive feature [ \pm Auth]. We could imagine a similar PCC that disallowed any combination of 1 st and 3rd person, called the "No Me \& Him PCC".

(83) Strong PCC: No combinations of contrastive [Auth] with different values allowed, e.g., $*<12>$ and $*<21>$ but $<23>$ and $<13>$ permissible.

(84) No Me\&Him PCC: No combinations of contrastive [Auth] with different values allowed, e.g., $*<13>$ and $*<31>$ but $<12>$ and $<32>$ permissible.

However, the No Me \& Him PCC system in (84) is ruled out because, given our features, 1 st and 3 rd person are not a natural class that shares a contrastive feature.

All three of these imaginable PCCs in (80), (82) and (84) are, to my knowledge, unattested. The feature system here thus makes three falsifiable predictions about impossible PCCs. This is exactly what one should want from a feature system for Person: one that generates all of the attested patterns and makes predictions about logically possible but UG-impossible patterns.

\subsection{Interim summary}

We have thus considered an account of the range of crosslinguistic PCC effects that does not rely upon the 3 noP view, and contains full specification of features for all clitics/pronouns, yet allows for flexibility and variation in the functional heads that control agreement, which may bear varying degrees of parametrization as to the values they will allow in Multiple Agree scenarios when there are two arguments within the domain. In the next sections, we explore related questions that arise given a proposal of this nature. 


\section{Why [ \pm Hearer] probably does not exist}

The definitions of contrastiveness and markedness and how they are used to single out particular combinations of features here depend very heavily on the featural specifications I have adopted for person, namely [Participant] and [Author]. It is therefore important to explore what would happen with a different feature system. In particular, one might wonder about a binary feature that specifically creates an opposition between 2 nd person and non-2nd person.

One of the few morphologically motivated arguments for such a feature is syncretism between 1 st and 3rd person, which share the putative value [ $-2 \mathrm{nd}]$. Nevins (2003) argues that the Germanic instantiation of this syncretism should be handled by an impoverishment rule, rather than being the consequence of idiosyncratic vocabulary items specified for [-2]. A markedness-based impoverishment rule which renders 1st person featurally identical to 3rd enforces the rigidity of this syncretism and disallows innovation of a new 1st-specific vocabulary item. ${ }^{24}$ Therefore no appeal to $[ \pm 2]$ is needed for this case.

Despite the paucity of morphologically based motivation for the feature [Hearer] (or at least, its independent necessity, given [Participant] and [Author]), it is important to explore how it would interact within the current system of value-based relativization.

In the first section, I will demonstrate that for systems without an inclusive/exclusive distinction (i.e., systems without "clusivity"), a binary feature [ \pm Hearer] undergenerates, no matter what the other features are. In the second section, I will briefly discuss the arguments for a privative feature [addressee] in languages with clusivity.

\section{$7.1[ \pm$ Hearer $]$ in systems without clusivity}

Suppose we were to completely replace the feature [Author] with [Hearer] instead, and simply invert the values, so that 1 st was [-Hearer], 2nd was [+Hearer], and 3rd was [-Hearer]. In addition, of course, [+Hearer] would need to be the marked value of [Hearer], otherwise this would simply become a notational variant of what I have already adopted here.

$$
\begin{aligned}
& \text { Person specifications using }[ \pm \text { Participant }],[ \pm \text { Hearer }] \text { : } \\
& \begin{array}{l}
\text { 1st person }=[- \text { Hear },+ \text { Part }] \\
\text { 2nd person }=[+ \text { Hear },+ \text { Part }] \\
\text { 3rd person }=[- \text { Hear },- \text { Part }]
\end{array}
\end{aligned}
$$

Under this system, the prediction is that there would be no Me-First system of clitic ordering, contrary to fact (cf. (66)), and that there would be "you first!" systems of clitic ordering, which, as discussed in Sect. 6.5, are unattested. Thus, this system undergenerates (and possibly overgenerates).

\footnotetext{
${ }^{24}$ Nevins (2003) pursues a privative feature theory; however, a revision within the current system is straightforward. In particular, assume that in the marked environment of Past tense, the doublymarked combination [+Auth, + Part] is deleted, resulting in insertion of the elsewhere [-Plural] item (e.g., was).
} 
The second possibility to explore is one in which there were three separate person features, namely $[ \pm$ Part $],[ \pm$ Auth $]$ and $[ \pm$ Hearer $]$. Under such a system, there would be the following person specifications:

$$
\begin{aligned}
& \text { Person specifications using }[ \pm \text { Participant }],[ \pm \text { Author }],[ \pm \text { Hearer }] \text { : } \\
& \text { 1st person }=[+ \text { Auth },- \text { Hear },+ \text { Part }] \\
& \text { 2nd person }=[- \text { Auth },+ \text { Hear },+ \text { Part }] \\
& \text { 3rd person }=[- \text { Auth },- \text { Hear },- \text { Part }] .
\end{aligned}
$$

The problem with this system is that the definition of contrastiveness in (45) cannot be applied at all here, as there are no featural specifications that minimally contrast in the binary value of one feature. It is important to note that having both [ \pm Auth] and $[ \pm$ Hearer] causes problems for contrastiveness because the two are incompatible, not because there are more than two features. Adding number and gender features will have no effect for the definition of contrastiveness. (Unless there were some nonUG inventory that ruled out combinations of certain persons with certain genders or numbers, e.g., disallowed [-Part, - Auth $]$ and $[+$ Fem $]$ in the same feature bundle.) Thus, the inclusion of $[ \pm$ Hear] in a system that already has $[ \pm$ Auth] comes from the incompatibility, not from the number of features.

Since contrastiveness cannot be used to derive PCC effects, we can consider other relativizations that could be used. Marked [+Part] would yield the weak PCC, and Marked [+Auth] would yield the Me-First PCC, while Marked [+Hear] would yield the unattested "you first" system. However, there is no combination that would yield the strong PCC given the existing conditions on Multiple Agree, i.e., there is no way to rule out $<2 \quad 1>$ and $<12>$ using parametrization to marked features only.

As a final possibility, we may consider a system that replaces [Participant] altogether with [ \pm Hearer]. Clearly such a system cannot straightforwardly capture $1 / 2$ versus 3 patterns in the morphology, though it is of course possible using alpha notation (cf. for example Noyer, 1992, who explores [ $\alpha$ Author, $-\alpha$ Hearer] as a means to group $1 / 2$ versus 3$)$.

(87) Person specifications using [ \pm Author], $[ \pm$ Hearer $]$ :

$$
\begin{aligned}
& \text { 1st person }=[+ \text { Auth },- \text { Hear }] \\
& \text { 2nd person }=[- \text { Auth },+ \text { Hear }] \\
& \text { 3rd person }=[- \text { Auth },- \text { Hear }] .
\end{aligned}
$$

Given these two binary features, we would re-evaluate which features are contrastive. 1st person is contrastive for [Author] but not [Hearer], 2nd person is contrastive for [Hearer] but not [Author], and 3rd person is contrastive for both features. Note that it becomes perhaps more difficult to define markedness on features in a context-free way in this system (i.e. to follow the intuition that 1st person is doubly marked, hence subject to many more syncretisms in its environment), but we can tentatively assume that the positive values of both features are marked.

We would thus expect the following PCC effects: 
(88) Multiple Agree in a [ \pm Author $]$ and $[ \pm$ Hearer $]$ system:

Contrastive-[Hearer]: *1 2 (by CA), *1 3 (by CA), *2 3 and *3 2 (by MV)

Contrastive-[Author]: *2 3 (by CA), *2 1 (by CA), *3 1 and *1 3 (by MV)

Marked-[Hearer]: *1 2 (by CA), *3 2 (by CA)

Marked-[Author]: *2 1 (by CA), *31 (by CA).

Note that to express the weak PCC would, at minimum, require a conjunction of two relativizations (since none of the single restrictions in (88) rule out both $<32>$ and $<31>$ ). The strong PCC likewise requires a conjunction (since none of the single restrictions in (10) rule out both $<12>$ and $<21>$ ). We can summarize the possibilities of relativization adopting the feature system in (88):

Combinatorial possibilities yielding a PCC typology with only $[ \pm$ Auth $],[ \pm$ Hear $]$

\begin{tabular}{|c|c|c|c|}
\hline & All [Auth] & Contrastive [Auth] & Marked [Auth] \\
\hline All [Hear] & No PCC & You-last & $\begin{array}{l}\text { Me-first with } \\
<32>\text { ok }\end{array}$ \\
\hline Contrastive [Hear] & Me-last & Impossible & Impossible \\
\hline Marked [Hear] & $\begin{array}{l}\text { You-first with } \\
<31>\text { ok }\end{array}$ & Impossible & strong PCC \\
\hline
\end{tabular}

The cells marked Impossible would rule out all 6 possible clitic orders. Regarding the other cells, recall that since 1 st is not contrastive for [Hearer], a contrastive relativization for [Hearer] allows only $<31>$ and $<21>$, yielding a "me-last" system. Note that there are two other PCC possibilities that this system predicts, such as "you-last" and "you-first", which are not attested.

However, the most striking thing about these combinations is that none of them yield the weak PCC. That is, no combination rules out $<32>$, and $<31>$ and allows all other combinations. This is thus the major shortcoming of such a system. It arises because there is no way to group $1 / 2$ as having to precede 3 , which can be straightforwardly done with Marked [Participant] relativization, if one admits such a feature, as I have done here.

To conclude this subsection, we have considered three possible alternative person feature systems that involve the putative feature [Hearer]. A system in which [Hearer] replaces [Author] undergenerates: as it cannot refer to the marked [Author] feature characterizing 1st person alone, it fails to yield the attested Me-First PCC. A system in which [Hearer] accompanies the existing [Author] and [Participant] undergenerates: as it is overly featurally rich, 1st and 2nd person no longer are contrastive for [Author], so it fails to yield the attested strong PCC. Finally, a system in which [Hearer] replaces [Participant] undergenerates: as it cannot refer to the marked [Participant] feature, it fails to yield the attested weak PCC. These results are summarized in the table below, where $\otimes$ indicates failure to capture a PCC. 
(90) PCC effects as captured by varying Person feature inventories involving $[ \pm$ Hearer $]$

\begin{tabular}{llll}
\hline Person feature inventory & $\begin{array}{c}\text { captures weak } \\
\text { PCC }\end{array}$ & $\begin{array}{l}\text { captures strong } \\
\text { PCC }\end{array}$ & $\begin{array}{l}\text { captures } \\
\text { Me-First PCC }\end{array}$ \\
\hline$\{[ \pm$ Auth $],[ \pm$ Part $]\}$ & $\star$ & $\star$ & $\star$ \\
$\{[ \pm$ Hear $],[ \pm$ Part $]\}$ & $\star$ & $\star$ & $\otimes$ \\
$\{[ \pm$ Auth $],[ \pm$ Hear $]\}$ & $\otimes$ & $\star$ & $\star$ \\
$\{[ \pm$ Auth $],[ \pm$ Part $],[ \pm$ Hear $]\}$ & $\star$ & $\otimes$ & $\star$ \\
\hline
\end{tabular}

The feature [Hearer] thus receives no support from PCC effects. Its inclusion in any system of person features yields a basic inability to predict the typology of attested PCC effects within the syntactic approach developed here.

\section{2 [Addressee] in systems with clusivity}

We have seen in the previous section that $[ \pm$ Hearer] does nothing but cause problems in predicting a typology of PCC effects. However, we have left open thus far the featural distinction between 1st person inclusive and exclusive in systems that distinguish these two categories.

In understanding 3-person systems, I have employed the binary features [ \pm Author] and $[ \pm$ Participant]. I would like to propose that languages with an inclusive/exclusive distinction incorporate an additional feature, [addressee], which is privative, and hence lacks a distinction between + and - values. ${ }^{25}$

$$
-\mathrm{F}=\neg[+\mathrm{F}]
$$

a. $[+$ Auth $]=$ the reference set contains the speaker

b. $[+$ Participant $]=$ the reference set contains one of the discourse participants

c. $[$ addressee $]=$ the reference set contains the addressee

The features composing the person categories in a system with clusivity are thus the following.
a. $[+$ Auth,+ Part $]=1$ st person exclusive
b. $[+$ Auth,+ Part $][$ addr $]=1$ st person inclusive
c. $[-$ Auth,+ Part $][$ addr $]=2$ nd person
d. $[-$ Auth, - Part $]=3$ rd person
e. $[-$ Auth, - Part $][$ addr $]=$ logically impossible
f. $[+$ Auth, - Part $]=$ logically impossible

25 Harbour (2006), at the time of writing, has independently proposed that the existence of imperative verb forms that are specialized for an addressee (but which do not constitute a paradigm with the morphological expression of hortatives or jussives) provides evidence for a privative [addressee] feature. 
Recall from the definitions that I have provided for contrastive (45) and marked (as in (47)) that they only are defined over binary features. The prediction, then, is that [addressee] can never play a role in conditioning PCC effects. The prediction is thus that a system with clusivity will never distinguish 1st-inclusive from 1st-exclusive with respect to PCC effects. This is a falsifiable prediction, which deserves further research. As far as I have looked in five languages that both (a) have an inclusive/exclusive distinction, and (b) show PCC effects, the prediction is upheld for Kiowa (Kiowa-Tanoan family; Daniel Harbour, pers. comm., November 2005), Passamaquoddy (Algonquian family; Leavitt, 1996, Benjamin Bruening and Conor Quinn, pers. comm. March 2006), Yimas (Foley, 1991: 212-214) Warlpiri (Pama-Nyungan; Hale, 1973: 332-338), Julie Legate, pers. comm., May 2006), and Chinook (Silverstein, 1976: 190-194) for which the authors make no mention of inclusive and exclusive $1 \mathrm{pl}$ ever behaving differently with respect to ditransitive restrictions.

The only grammatical purposes of [addressee] are interpretive (in the sense that the assertion that the addressee is in the reference set is interpreted), and to condition syncretism (witness, e.g., the syncretism between 2 nd person and inclusive-we found in Algonquian prefixes, as discussed in McGinnis (2005)). I assume that [addressee] is only activated in systems with clusivity when there is positive evidence for its necessity, following McGinnis (2005).

For the sake of completeness, let us consider here the consequences of adopting a binary feature $[ \pm$ Hearer $]$ for systems with clusivity.

(93) Putative 3-binary feature system
a. $[+$ Auth,+ Part,- Hear $]=1$ st person exclusive
b. $[+$ Auth,+ Part,+ Hear $]=1$ st person inclusive
c. $[-$ Auth,+ Part,+ Hear $]=2$ nd person
d. $[-$ Auth, - Part,- Hear $]=3$ rd person
e. $[-$ Part,+ Hear $]=$ logically impossible
f. $[-$ Part,+ Auth $]=$ logically impossible

There are two pairs that are contrastive for a single feature under this scenario:

a. 1st-inclusive and 1st-exclusive: contrastive for $[ \pm$ Hearer $]$

b. 2nd and 1st-inclusive: contrastive for [ \pm Author]

Thus, in a system with relativization of the goal to contrastive values, these combinations would be predicted to be ruled out. Nonetheless, we might be able to dismiss (94a) and (94b) as impossible dative-accusative combinations in any event, on pragmatic grounds (i.e. it might be odd for John to introduce us-inclusive to us-exclusive (since the author is in both groups), and weird for John to introduce you to us-inclusive (since the addressee is in both groups).

Importantly, however, under a contrastive relativization of $[ \pm$ Author $]$ given the feature specifications in (93), the system could never capture any strong PCC effect, 
as 1st and 2nd person are not contrastive. This is thus a clear shortcoming of the feature system in (93). In the system for clusivity with a privative [addressee] feature that I am proposing in (92), I predict no difference in the typology of PCC effects between clusive and non-clusive languages. This is a falsifiable prediction that deserves further research.

\subsection{Interim Conclusions}

In short, we have seen that the features [ \pm Author] and [ \pm Participant] are more successful in generating the typology of PCC effects than alternatives which include the binary feature $[ \pm$ Hearer]. I have proposed that languages with a clusive distinction may activate a privative feature [addressee] for interpretive purposes of distinguishing 1st-inclusive from 1st-exclusive and for purposes of expressing syncretism, but that this feature plays no role in conditioning PCC effects.

The fact that $[ \pm$ Author $]$ and $[ \pm$ Participant $]$ yield the typology of attested and unattested PCC effects more successfully than other possible systems of binary features thus supports in turn the more general conclusion that these are the only binary person features of natural language. Returning to 3rd person, then, it seems best represented as [-Author,-Participant]. In the next section, we turn to a difference between $3 \mathrm{rd}$ persons and impersonals/reflexives.

\section{The representation of reflexives and impersonals}

Given the distinction above, all existing grammatical analyses that posit that " 3 rd person has no person" simply need to replace this statement with the Probe's search is relativized to contrastive values of [Author]. As there is no [-Part, + Auth] pronoun in the inventory, [Auth] is not contrastive for 3rd person. When two contrastive values of [Author] are found, Anagnostopoulou's constraint on Multiple Agree can apply and correctly rule out PCC configurations; at the same time, the features [-Part,-Auth] are present on 3rd person arguments, and this will avoid the problem noted in Sect. 1.

Thus, as noted above, we can distinguish the 'weak' and 'strong PCC' by relativization of the search domain, placing the locus of variation within the lexical properties of the Probe, rather than in wholly different syntactic mechanisms.

The important question now, however, is the featural difference between 3rd person and impersonals/reflexives. This question arises in any feature-based system of person representation, though it does not figure into the proposals of Noyer (1992), Halle (1997), or Harley and Ritter (2002), the most influential person-feature proposals to date. My own remarks on the topic will be rather preliminary here. First, it is important to distinguish between impersonals and reflexives. I will assume that impersonals have disjunctive specifications, i.e., they syntactically bear all feature specifications simultaneously, as proposed by D'Alessandro (2004):

$$
\begin{aligned}
& \text { Interpretive possibilities for Impersonal pronouns: } \\
& \{[+ \text { Participant },+ \text { Author }] \cap[+ \text { Participant,-Author }] \\
& \cap[\text {-Participant,-Author }]\}
\end{aligned}
$$

The representational vocabulary for expressing this disjunctive specification is open to investigation. I will make a concrete proposal here: impersonals have no specification 
for $[ \pm$ Participant] or for [ \pm Author]. As such, they will trivially satisfy the MatchedValue constraint, if it is to be interpreted as a non-contradiction in feature-values.

(96) Representation of Impersonal pronouns: [ØParticipant, ØAuthor]

Note in (96) that a $\emptyset$ value for a feature $F$ is compatible with both + and - values. Impersonal pronouns are thus differentiated from 3rd person pronouns in that they truly are underspecified for Person features. Indeed, their interpretation, as shown by D'Alessandro, is precisely that they are compatible with any antecedent. ${ }^{26}$ and thus, unlike the case of 3rd person pronouns (which we know are not [+Participant], and hence are specified as [-Participant]), it does make sense to claim that impersonals are underspecified (see Burzio, 1986, Manzini, 1986 for proposals that Italian impersonal si lacks a specification for person). Impersonal pronouns can in principle refer to any person specification, though pragmatics usually strongly favors one over the others. The consequences of this underspecification-based implementation for the PCC will be explored below.

In contrast to impersonals, the representation of reflexives is subject to a great deal more crosslinguistic variation. When reflexives do not participate in PCC effects and do not differentiate person (e.g., Bulgarian, Rivero, 2004), they can clearly become assimilated to the above statement (96); they are disjunctive, like impersonals. ${ }^{27}$ There are, however, languages, which differentiate reflexives for person; in Spanish, the same 1st/2nd clitic pronouns $m e$ and te which are used for dative/accusative are used for

26 Kratzer (1997) provides examples of German impersonal man being bound by a 1st person antecedent:

(i) Wenn ich Kinder hätte, könnte man zusammen Monopoly spielen.

If I children had could MAN together Monopoly play.

If I had children, we could play Monopoly together.

(ii) Als ich klein war, wurde man nur am Freitag gebadet

When I little was got MAN only on Friday bathed

When I was little, one only bathed on Fridays.

Indeed, even the English translation of (ii) is compatible with an interpretation of the impersonal that includes the speaker. D'Alessandro(2004, Chap. 5) provides an extensive discussion of the role of Aktionsart and sentential aspect in identification of the reference set of Italian si, which can often yield a reading that includes the speaker, as in (iii).

(iii) Ieri si è arrivati tardi in stazione

Yesterday si is arrived late in station

Yesterday, we arrived late at the station.

27 Rural dialects of Brazilian Portuguese have general-purpose reflexive clitics while at the same time maintaining distinct object clitics (Nadir de Lima, pers. comm., May 2006). Thus, while (i) requires a 1st-person object clitic for a direct object, (ii) employs the general reflexive se even in the presence of a 1 st person pronoun and agreement.

(i) Você me viu

You 1obj-cl. saw.past-2sg.

You saw me.

(ii) Euse machuquei

I reflexive-cl. hurt.past-1sg.

I hurt myself.

These data, collected from speakers from Minas Gerais, support the grammatical possibility of disjunctive reflexive clitics compatible with any person while maintaining 1st-person object clitics at the same time. 
reflexives. In line with the current proposal, person-distinguished reflexives bear the same person features as their non-reflexive counterparts in the syntax (although they differ in their Case features; see Bonet, 1991). Thus, in terms of the PCC, personmarked reflexives are expected to pattern just like person-marked clitics with other Case features.

Thus, on the assumption that the Dative is higher than the Person-marked reflexive in the underlying syntax of the clauses that contain a dative and a reflexive, an intervening 3rd-reflexive (which is [-Part,-Auth]) will fall prey to the same violation of the Contiguous Agree condition as an intervening 3rd dative: both lack contrastive values for [Author]. As Rivero (2004) demonstrates, this prediction is upheld: $<32>$ and $<31>$ sequences, in which the underlying leftwards dative c-commands the $1 \mathrm{st} / 2 \mathrm{nd}$ reflexive, result in weak PCC violations that are identical to those encountered by 3 rd datives that c-command a 1 st/2nd accusative.
A Ana siempre se le antojan los mismos chicos

to Ana always refl dat-3rd fancy-3pl the same guys

Ana always takes a fancy to the same guys. (Spanish; Rivero, 2004:496)

(98) *A Ana siempre nos le antojamos nostros

to Ana always 1pl-refl dat-3rd fancy-1pl us

Ana always takes a fancy to us.

(Spanish; Rivero, 2004:496)

\section{*A Ana siempre os le antojais vosotros to Ana always 2pl-refl dat-3rd fancy-2pl you-pl.}

Ana always takes a fancy to y'all.

(Spanish; Rivero, 2004:496)

Clearly, person-marked reflexives behave identically to person-marked datives and accusatives. Returning to the representation of all-purpose reflexives and impersonals, however, we may note that by virtue of its disjunctive specification, an all-purpose reflexive will allow for a convergent derivation under Multiple Agree. A relevant language in which to test this prediction is Bulgarian, which has a PCC for dativeaccusative combination (100).

(100) *Az im te preporâchvam

I 2-acc 3-dat recommend-prog

I am recommending you to them.

(Rivero, 2004: 500)

Though we do not know on the basis of this example whether it is the weak or strong PCC, let us assume it is the weak one. Since we can conclude based on the dativeaccusative combination in (100) that Bulgarian has a PCC, we may now ask what happens if there is an all-purpose reflexive present in the domain of $v$.

Suppose we interpret (100) to indicate the Bulgarian has the weak PCC. Given a relativization of the Probe to marked values of [Participant], a downstairs all-purpose reflexive need not be included in the domain of Multiple Agree: by bearing no value for [Participant] or [Author], indeed, the all-purpose reflexive remains outside of the domain of Agree. Thus, the Contiguous Agree condition is trivially met, as neither argument is within the domain. ${ }^{28}$ Thus, all-purpose reflexives, even when coreferent with $1 / 2$ arguments, never give rise to PCC effects, by virtue of their lack of specification for [Author] or [Participant]. Indeed, any dative clitic can dominate a reflexive:

28 Consider the scenario in which this is a strong PCC effect. In this case, there would be relativization to the contrastive value of [Author]. If the upstairs dative were 1st or 2nd person, by virtue of its non-specification, the downstairs reflexive would trivially meet the condition on Matched Values due to non-contradiction. 
(101) Na Ivan mu (se) xaresvat tezi momicheta

to Ivan dat (refl) like-3pl these girls

Ivan likes these girls.

(Bulgarian; Rivero, 2004:500)

(102) Na Ivan mu (se) xaresvame nie.

to Ivan dat-3rd (refl) like-1pl us

Ivan likes us.

(Bulgarian; Rivero, 2004:500)

(103) Na Ivan mu (se) xaresvate vie.

to Ivan dat-3rd (refl) like-2pl 2pl

Ivan likes y'all.

(Bulgarian; Rivero, 2004:500)

From the Bulgarian facts, in contrast to the Spanish facts, we can conclude that whether or not a reflexive is underspecified for person will have consequences for its behavior in PCC configurations. Thus, concerning reflexives and impersonals, there is no general-purpose answer as to how they will behave with respect to the PCC: it depends on whether they are person-specific reflexives or not. The predictions of the current account are thus summarized in (104).

(104) a. Person-specific reflexives (i.e. Spanish me): behave like corresponding accusative arguments with respect to the PCC

b. Impersonals and all-purpose reflexives: immune to PCC due to $\emptyset$-value for [Author] and [Participant]

Importantly, then, although one of the major conclusions of this paper has been that 3rd person is fully specified as [-Author, -Participant] and that underspecification is inappropriate for modeling both spurious se and PCC effects that refer to these features, impersonals and all-purpose reflexives can be underspecified for Person features, and in fact are representationally distinguished from 3rd person in precisely this way.

Returning to the facts at the outset of this paper regarding the spurious se rule of Spanish, recall that we motivated the structural description of this rule as a dissimilation rule, banning adjacent [-Participant] specifications. We are now in a position to discuss the structural change that repairs this banned configuration.

(105) Spurious se rule:

a. Structural description: $[- \text { Participant }]_{\text {Dative }}[\text {-Participant }]_{\text {Accusative }}$

b. Structural change: Delete [-Participant,-Author] on the Dative

The structural change in $(105 \mathrm{~b})$ removes the offending feature banned by this dissimilatory constraint on adjacent identical featural specifications. The result of the structural change is lack of a value for both [ \pm Participant] and [ \pm Author]. It is therefore not a surprise that the clitic that surfaces in this position is precisely the one corresponding to the lack of these features: the impersonal clitic se.

\section{Conclusion}

I have attempted to present an implementation of Person-Case effects in terms of the syntactic operation Multiple Agree (Hiraiwa, 2001) operating within the search-space of $v$ on indirect and direct object clitics, and motivated an extension of Calabrese's (1995) theory of value-relativized parametrization in phonology to an illumination of featural visibility in the morphosyntactic domain. Crucial to this account has been 
the proposal that markedness and contrastiveness are properties of Person features to which the grammar can refer.

The proposal that 3 rd person is always featurally represented as [-Author,-Participant] has been shown to have three positive consequences:

(106) a. It enables an understanding of the spurious se effect as the consequence of a well-motivated morphological dissimilation rule.

b. It enables a restrictive typology of syntactically-based Person-Case effects, including the Me-First pattern of Romanian which disallows $<31>$ but allows $<32>$

c. It enables a representational distinction between $3 \mathrm{rd}$ person and impersonal pronouns that facilitates a contrast in their interpretive possibilities.

Person is a category with morphological, syntactic, and interpretive consequences, and features are the basic currency of grammatical relations and operations. Crossmodular representational commensurability is thus an important desideratum for natural language, and for linguistic theory.

\section{References}

Adger, D., \& Harbour, D. (2006). The syntax and syncretisms of the person case constraint. To appear in Syntax.

Anagnostopoulou, E. (2003). The syntax of ditransitives. Berlin: Mouton de Gruyter.

Anagnostopoulou, E. (2005). Strong and weak person restrictions: A feature checking analysis. In L. Heggie \& F. Ordoñez (Eds.), Clitics and Affixation (pp. 199-235). Amsterdam: John Benjamins.

Anttila, A. (2003). Finnish assibilation. In M. Kadowaki \& S. Kawahara (Eds.), The Proceedings of NELS 33, (pp. 13-24). Amherst, MA: GLSA.

Archangeli, D. (1984). Underspecification in Yawelmani phonology and morphology. Doctoral Dissertation, MIT.

Arregi, K., \& Nevins, A. (2006). Obliteration vs. impoverishment in the Basque g-/z-constraint. In T. Scheffier (Eds.), Penn linguistics colloquium special session on distributed morphology, U. Penn Working Papers in Linguistics 13.1. (Also available as at http://ling.auf.net/lingBuzz/000280).

Avery, P., \& Rice, K. (1989). Segment structure and coronal underspecification. Phonology, 6, 179-200. Bejar, S. (2003). Phi-Syntax: A theory of agreement. Doctoral Dissertation, University of Toronto.

Bejar, S., \& Rezac, M. (2003). Person licensing and the derivation of PCC effects. In Y. Roberge \& A. T. Pérez-Leroux (Eds.), Romance linguistics: Theory and acquisition (pp. 49-62). Amsterdam: John Benjamins.

Benveniste, E. (1971). Problems in general linguistics. Coral Gables, FL: University of Miami Press.

Bianchi, V. (2005). On the syntax of personal arguments. Lingua, 116(12), 2023-2067.

Bleam, T. (1999). Leísta Spanish and the Syntax of Clitic doubling. Doctoral Dissertation, University of Delaware.

Bonet, E. (1991). Morphology after syntax: pronominal clitics in romance. Doctoral Dissertation, MIT.

Bonet, E. (1995). Feature structure of Romance clitics. Natural Language and Linguistic Theory, 13, 607-647.

Borer, H. (1984). Parametric syntax. Dordrecht: Foris.

Bresnan, J. (2001). Explaning morphosyntactic competition. In M. Baltin \& C. Collins (Eds.), The handbook of contemporary syntactic theory (pp. 11-14). Malden, MA: Blackwell.

Bruening, B. (2001). QR obeys superiority: ACD and frozen scope. Linguistic Inquiry, 32(2), 233-273.

Burzio, L. (1986). Italian syntax, Studies in natural language and linguistic theory. Dordrecht: Kluwer.

Cagliari, L. C. (1997). Fonologia do Português: Análise pela geometria de traços. Campinas: Edição do Autor.

Calabrese, A. (1995). A constraint-based theory of phonological markedness and simplification procedures. Linguistic Inquiry, 26, 373-463.

Chomsky, N. (2001). Minimalist inquiries: The framework. Cambridge MA: MITWPL.

Chomsky, N., \& Halle, M. (1968). The sound pattern of English. New York: Harper and Row. 
Ciucivara, O. (2004). Syntactic analysis of pronominal clitic combinations in Romanian. Ms., NYU.

D'Alessandro, R. (2004). Impersonal si constructions: Agreement and interpretation. Doctoral Dissertation, Universität Stuttgart.

de Yrizar, P. (1992). Morfología del verbo auxiliar vizcaino: estudio dialectológico. Bilbao Bizkaia Kutxa: Euskaltzaindia.

Farkas, D., \& Kazazis, K. (1980). Clitic pronouns and topicality in Rumanian. Chicago Linguistic Society, 16, 75-82.

Fassi-Fehri, A. (1988). Agreement in Arabic, binding and coherence. In M. Barlow \& C. Ferguson (Eds.), Agreement in natural language (pp. 107-158). Stanford: CSLI.

Fernández-Soriano, O. (1999). El Pronombre Personal. Formas y distribuciones. Pronombres Átonos y Tónicos. In I. Bosque \& V. Demonte (Eds.), Gramática Descriptiva de la Lengua Española (pp. 1209-1273). Chapter 19. Madrid: Espasa Calpe.

Foley, W. (1991). The Yimas language of New Guinea. Stanford: Stanford University Press.

Forchheimer, P. (1953). The category of person in language. Berlin: Walter de Gruyter.

Francis, N. (1985). Amn't I, or the hole in the pattern. In W. Viereck (Ed.), Focus on England and Wales (pp. 141-152). Amsterdam: John Benjamins.

Franco, J., \& Huidobro, S. (2004). Experiencer Datives and Belleti's and Rizzi's second class of Psych verbs. In S. Bračič et al. (Eds.), Proceedings of the 36th linguistic colloquium, Ljubljana, 2001 (pp. 219-229).

Grimshaw, J. (1997). The best clitic: Constraint interaction in morphosyntax. In L. Hargeman (Ed.), Elements of grammar (pp. 169-196). Dordrecht: Kluwer.

Hale, K. (1973). Person marking in Warlbiri. In S. Anderson \& P. Kiparsky (Eds.), A Festschrift for Morris Halle. (pp. 308-344). New York: Holt, Rinehart and Winston.

Hall, T., \& Hamann, S. (2006). Towards a typology of stop assibilation. To appear in Linguistics.

Halle, M. (1997). Impoverishment and Fission. In B. Bruening et al. (Eds.), PF: Papers at the interface, (Vol. 30, pp. 425-450). Cambridge, MA: MITWPL.

Halle, M., \& Marantz, A. (1993). Distributed morphology and the pieces of inflection. In K. Hall \& S. J. Keyser (Eds.), The view from building (Vol. 20, pp. 111-176). Cambridge, MA: MITWPL.

Harbour, D. (2003a). Elements of number theory. Doctoral Dissertation, MIT.

Harbour, D. (2003b). The Kiowa case for feature insertion. Natural Language and Linguistic Theory, 21(3), 543-578.

Harbour, D. (2006). Person hierarchies and geometry without hierarchies or geometries. Queen Mary's OPAL \#6.

Harley, H., \& Ritter, E. (2002). Person and number in pronouns: A feature-geometric analysis. Language, 78(3), 482-526.

Hiraiwa, K. (2001). Multiple agree and the defective intervention constraint in Japanese. In O. Matushansky (Ed.), The Proceedings of the MIT-Harvard joint conference (HUMIT 2000), MITWPL 40 (pp. 67-80). Cambridge, MA: MITWPL.

Hiraiwa, K. (2004). Dimensions of symmetry in syntax: Agreement and clausal architecture. Doctoral Dissertation, MIT.

Holmberg, A., \& Hróarsdóttir, T. (2004). Agreement and movement in Icelandic raising constructions. Lingua, 114, New York: 651-673.

Kayne, R. S. (2000). Parameters and Universals. New York: Oxford University Press.

Kiparsky, P. (1973). Phonological representations. In O. Fujimura (Ed.), Three dimensions of linguistic theory (pp. 3-136). Tokyo: TEC.

Kratzer, A. (1997). German impersonal pronouns and logophoricity. Paper presented at Sinn und Bedeutung II, Berlin.

Laenzlinger, C. (1998). Comparative studies in word order variation. Amsterdam: John Benjamins.

Landa, A. (1995). Conditions on null objects in Basque Spanish and their relation to Leismo and clitic doubling. Doctoral Dissertation, USC, Los Angeles.

Leavitt, R. (1996). Passamaquoddy-Maliseet. Munich: Lincom Europa.

Leben, W. (1973). Suprasegmental phonology. Doctoral Dissertation, MIT.

Manzini, R. (1986). On Italian si. In H. Borer (Ed.), Syntax and semantics: The syntax of pronominal clitics (pp. 241-262). New York: Academic Press.

Manzini, R. (1998). Syntactic approaches to cliticization. GLOT International, 3(3), 3-7.

McCarthy, J., \& Taub, A. (1992). Review of Paradis \& Prunet (Eds.), The special status of coronals. Phonology, 9, 363-370.

McGinnis, M. (2005). On markedness asymmetries in person and number. Language, 81(3), 699-718.

Miyagawa, S. (2001). EPP, scrambling, and Wh-in-situ. In M. Kenstowicz (Ed.), Ken Hale: A life in language (293-338). Cambridge, MIT Press. 
Mohanan, K. P. (1991). On the bases of radical underspecification. Natural Language and Linguistic Theory, 9, 285-325.

Nevins, A. (2003). Do person/number syncretisms refer to negative values? Paper presented at the 77th LSA Meeting, Atlanta.

Nevins, A. (2004). Conditions on (Dis)Harmony. Doctoral Dissertation, MIT.

Noyer, R. (1992). Features, positions and affixes in autonomous morphological structure. Doctoral Dissertation, MIT.

Ormazabal, J., \& Romero, J. (2006). The object agreement constraint. Natural Language and Linguistic Theory this volume.

Perlmutter, D. (1971). Deep and surface structure constraints in syntax. New York: Holt, Rinehart, and Winston.

Pescarini, D. (2005). Types of syncretism in the clitic systems of Romance. To appear International Journal of Basque Linguistics.

Rackowski, A., \& Richards, N. (2005). Phase edge and extraction: A Tagalog case study, Linguistic Inquiry, 36(4), 565-599.

Ramscar, M. (2002). The role of meaning in inflection: Why the past tense does not require a rule. Cognitive Psychology, 45(2), 45-94.

Ringen, C. (1975). Vowel harmony: theoretical implications. Doctoral Dissertation, Indiana University.

Rivero, M. (2004). Quirky subjects, person restrictions, and the person case constraint. Linguistic Inquiry, 35(3), 494-502.

Ross, J. R. (1972). Doubl-ing. Linguistic Inquiry, 3, 61-86.

Sedivy, J. C., Tanenhaus, M. K., Chambers, C. G., \& Carlson, G. N. (1999). Achieving incremental semantic interpretation through contextual representation. Cognition, 71, 109-147.

Silverstein, M. (1976). Hierarchy of features and ergativity. In R. M. W. Dixon (Ed.), Grammatical categories in Australian languages (pp.112-171). Canberra: Australian Institute of Aboriginal Studies.

Steriade, D. (1995). Underspecification and markedness. In J. Goldsmith (Ed.), The handbook of phonological theory (pp. 114-174). Malden, MA: Blackwell.

Trommer, J. (2006). Third person marking in Menominee. In Phi theory. Oxford: Oxford University Press. 